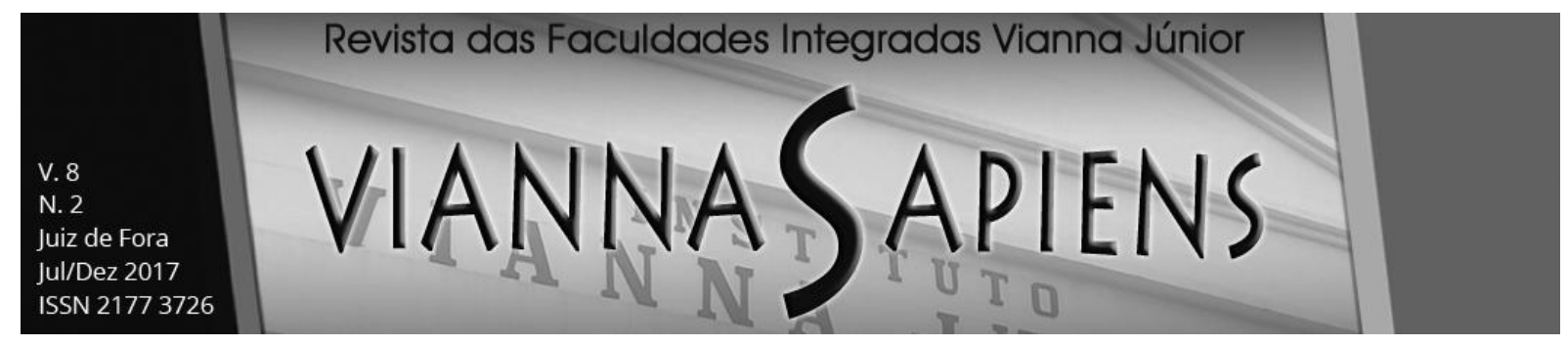

\title{
UMA ANÁLISE DA TECNOLOGIA DA INFORMAÇÃO SOB A ÓTICA DA SOCIOMATERIALIDADE
}

\author{
Emerson Augusto Priamo Moraes ${ }^{1}$ \\ Sandra Regina da Rocha-Pinto ${ }^{2}$
}

\section{RESUMO}

A tecnologia tem se tornado um aspecto integrante da maioria das organizações. De fato, as tecnologias estão em constante evolução e transformação, criando novos comportamentos e trazendo novos fenômenos aos pesquisadores para investigação no contexto em que se encontram. Especificamente na tecnologia da informação, observa-se uma mudança gradativa do campo de pesquisa, partindo de questões mais técnicas, ligadas à tecnologia, para uma visão mais voltada à organização, com informações gerenciais e estratégicas (ORLIKOWSKI e SCOTT, 2008). Esta mudança traz novos desafios para investigação na área, com abordagens promissoras, como a sociomaterialidade, que reconsidera o status da tecnologia na pesquisa organizacional. $\mathrm{O}$ objetivo deste trabalho é apresentar a sociomaterialidade como uma possível lente teórica para a condução de pesquisas sobre as implicações da TI nas organizações. Com esse objetivo, fundamentar-se-á na noção de que o aspecto sociomaterial não diz respeito à tecnologia, mas à prática, na qual a tecnologia está incorporada. A argumentação a ser desenvolvida neste ensaio,

\footnotetext{
${ }^{1}$ Professor efetivo do IF Sudeste MG. Doutor em Administração de Empresas pela PUC-Rio. Mestre em Sistemas de Gestão pela UFF. Project Management Professional pelo PMI. emerson.moraes@ifsudestemg.edu.br

${ }_{2}^{2}$ Professora assistente do Instituto de Administração e Gerência da PUC-Rio.da PUC-Rio, Doutora em Educação, Mestre em Administração de Empresas pela PUC-Rio. sanpin@iag.puc-rio.br
} 


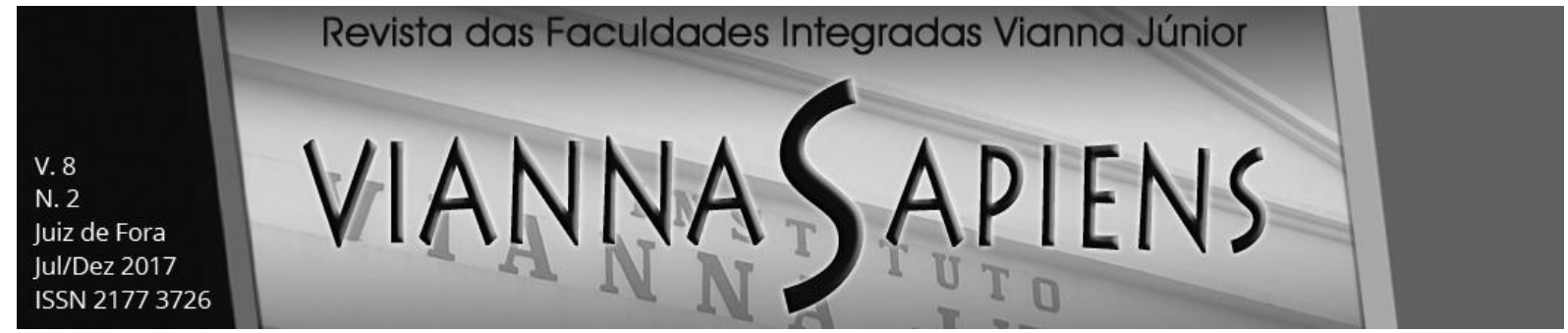

basear-se-á, essencialmente em três pontos: na visão de Orlikowski a respeito da sociomaterialidade; no estabelecimento de que a tecnologia pode ser representada e estudada por seus artefatos (responsáveis pela interação da tecnologia com os atores sociais); e na assunção de que as práticas são passíveis de interpretação por meio das rotinas organizacionais: criadas e estabelecidas, também, a partir da interação entre tecnologia e os atores sociais.

\section{PALAVRAS-CHAVE: TECNOLOGIA DA INFORMAÇÃO. ARTEFATOS DE TI. ROTINAS ORGANIZACIONAIS. SOCIOMATERIALIDADE.}

\section{INTRODUÇÃO}

As organizações precisam acompanhar as tendências e os eventos significativos que estão a ocorrer no ambiente externo para que possam se manter competitivas e sustentáveis em ambientes caracterizados por constantes mudanças (MORAES et al., 2004). Essas mudanças impõem aos gestores alguns desafios. Um deles situa-se em prover flexibilidade e agilidade aos novos modelos organizacionais. (LAURINDO, 2001). Em tal ambiente instável, a Tecnologia da Informação (TI) assume um papel de vital importância para a melhoria da competitividade das organizações; pode representar uma ferramenta estratégica para a análise de dados, transformando-os em informações confiáveis e atualizadas. A informação organizada modifica os processos de decisão, a estrutura administrativa e a maneira de trabalhar das empresas, possibilitando a execução de ações realmente úteis aos negócios (GABLE, 2010).

A TI torna a informação compreensível e aplicável na solução de problemas e na tomada de decisões que irão se transformar em diretrizes e pressupostos estratégicos, propiciando novas maneiras de obter vantagens em relação ao desempenho dos concorrentes (BORGES, 1995; PORTER e MILLAR, 1985). 


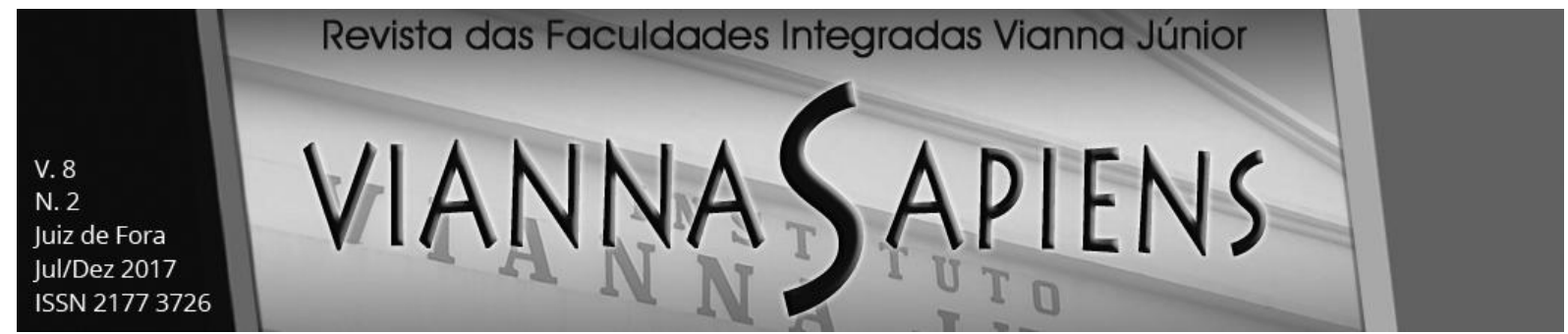

De fato, as tecnologias estão em constante evolução e transformação, criando novos comportamentos e trazendo novos fenômenos aos pesquisadores para investigação no contexto em que se encontram. Contudo, apesar de décadas de pesquisa e desenvolvimento de uma extensa literatura, bem como vários êxitos importantes, projetos de desenvolvimento de sistemas de software ainda são considerados problemáticos, com um número significativo de exemplos relacionados a desempenhos insatisfatórios (MCLEOD, MACDONELL e DOOLIN, 2011). Além disso, não são totalmente claras as formas de alcançar a harmonia entre a área de TI e seu impacto na organização. Assim, é possível questionar se as organizações estão adotando novos processos e se as estratégias utilizadas contemplam os benefícios que a TI pode oferecer (LUFTMAN, 1996).

A tecnologia tem se tornado um aspecto integrante da maioria das operações de negócios, seja um pequeno usuário de internet, um escritório de advocacia de médio porte, ou um grande fabricante de automóveis (ORLIKOWSKI e SCOTT, 2008). Difícil se pensar em qualquer organização contemporânea que, em algum nível, não dependa de algum tipo de tecnologia. Contudo, na medida em que a tecnologia é tratada como um fenômeno organizacional ocasional ou separado, perde-se a possibilidade de ver como ela é parte integrante de toda a organização em todos os tempos, lugares e circunstâncias. Ademais, especificamente na tecnologia da informação, observa-se uma mudança gradativa do campo de pesquisa, partindo de questões mais técnicas, ligadas à tecnologia, para uma visão mais voltada à organização, com informações gerenciais e estratégicas (ORLIKOWSKI e SCOTT, 2008).

Essa questão faz surgir novos desafios para investigação na área, com abordagens promissoras para reconsiderar o status da tecnologia na pesquisa organizacional, e assim aumentar o entendimento acerca das práticas da vida organizacional contemporânea. Tais abordagens são julgadas mais adequadas para métodos qualitativos, que permitem aprofundar o entendimento do fenômeno estudado. Nesse sentido, uma das possibilidades é a abordagem sociomaterial, 


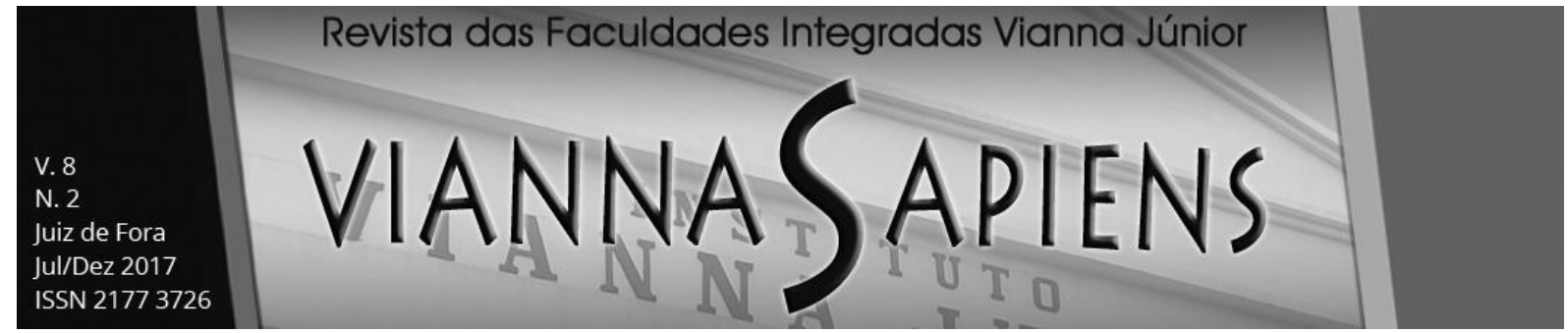

cujos princípios desafiam a premissa que a tecnologia, o trabalho, e as organizações devem ser conceituados separadamente, e avançam na opinião de que há uma ligação inseparável entre o técnico e o social (ORLIKOWSKI e SCOTT, 2008).

O objetivo deste trabalho é apresentar a sociomaterialidade como uma possível lente teórica para a condução de pesquisas sobre as implicações da $\mathrm{TI}$, e seus artefatos, nas organizações. Com esse objetivo, fundamentar-se-á na noção de que o aspecto sociomaterial não diz respeito à tecnologia, mas à prática, na qual a tecnologia está incorporada (ORLIKOWSKI e SCOTT, 2008). A argumentação a ser desenvolvida neste ensaio, basear-se-á, essencialmente em três pontos: na visão de Orlikowski a respeito da sociomaterialidade; no estabelecimento de que a tecnologia pode ser representada e estudada por seus artefatos (responsáveis pela interação da tecnologia com os atores sociais); e na assunção de que as práticas são passíveis de interpretação por meio das rotinas organizacionais: criadas e estabelecidas, também, a partir da interação entre tecnologia e os atores sociais.

Este artigo está estruturado em quatro seções, incluindo esta introdução. A segunda seção traz o referencial teórico selecionado para a discussão proposta. $\mathrm{Na}$ terceira seção tem-se uma pesquisa realizada nos artigos da ANPAD (Associação Nacional de Pós-Graduação e Pesquisa em Administração), sobre os temas abordados nesse trabalho. A quarta e última seção trazem as considerações finais do trabalho, ponderações e a proposta de novos caminhos de pesquisa.

\section{REFERENCIAL TEÓRICO}

Apresentam-se, em três tópicos considerações sobre Sociomaterialidade, Artefatos de Tecnologia da Informação e Rotinas Organizacionais. 


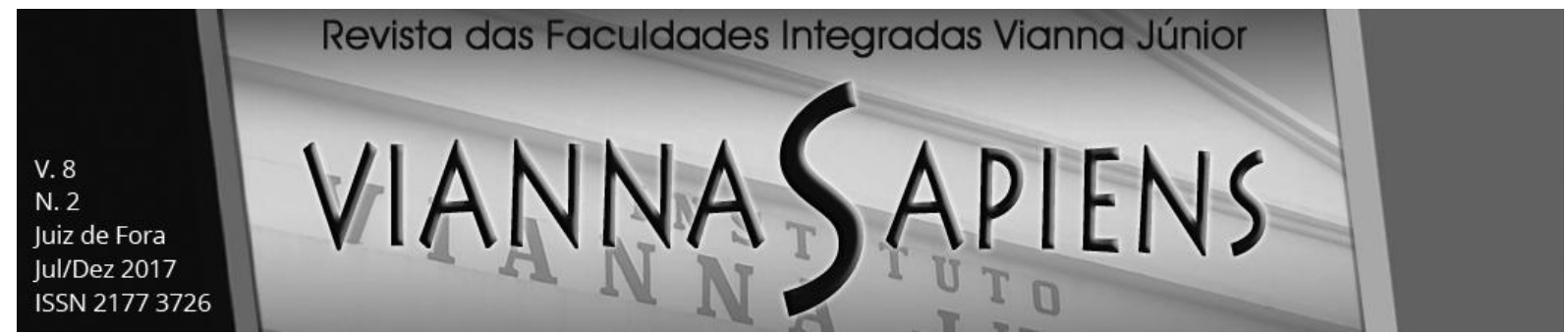

1.1 Sociomaterialidade: uma breve apresentação

Orlikowski e Scott (2008) ponderam que, embora se possa dizer que a tecnologia tem certa materialidade, faria pouco sentido falar de sociomaterialidade de uma tecnologia, sem considerar a prática. A prática é o espaço em que o social e o material estão constitutivamente entrelaçados. Embora a maioria dos estudos se ocupam em mostrar que social e o material são completamente interligados, os estudiosos estariam apenas começando a considerar como ocorre tal entrelaçamento. Os autores argumentam também que a materialidade é intrínseca às atividades diárias e suas relações com o social. Como um teste, sugerem ao leitor considerar fazer qualquer coisa no mundo (seja em casa, na estrada ou em organizações) que não implique, de alguma forma, meios materiais (por exemplo, corpos, roupas, alimentos, espetáculos, edifícios, salas de aula, dispositivos, papel, telefone, e-mail, etc.).

O entrelaçamento entre o social e o material não privilegia os seres humanos ou a tecnologia (em interações de sentido único), nem os liga por meio de uma forma de reciprocidade mútua (em interações de duas vias). Em vez disso, o social e o material são considerados intimamente relacionados - não há social que também não seja material, e não há material que não seja também social (ORLIKOWSKI, 2007). A sociomaterialidade muitas vezes ocorre em conjunto com a tecnologia e seus artefatos, que compõem parte da materialidade envolvida na questão.

Em relação à relevância da tecnologia, Orlikowski e Scott (2008) apontam que, do ponto de vista dos fenômenos organizacionais, a tecnologia parece estar em toda parte no mundo da prática. Um exemplo: orçamentos anuais corporativos para a gama de tecnologia se elevam na faixa dos bilhões de dólares para as grandes empresas, e os gastos em tecnologia são, para muitas empresas, o seu maior investimento. Apesar dessa importância, Orlikowski e Scott (2008) constatam que do ponto de vista da pesquisa organizacional, a tecnologia é expressivamente ausente do mundo da organização, uma vez que, ao longo da última década de pesquisa em 


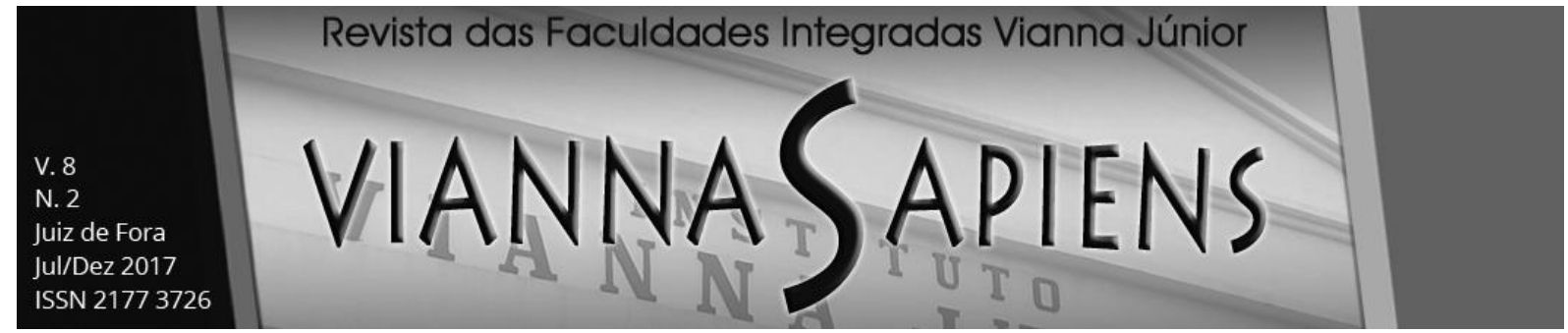

administração, mais de 95\% dos artigos publicados nas principais revistas de gestão não consideraram ou levaram em conta o papel e a influência da tecnologia na vida organizacional. As pesquisas enquadradas de acordo com os princípios de uma abordagem sociomaterial, desafiam profundamente a suposição que a tecnologia, o trabalho e as organizações devem ser conceituados separadamente (ORLIKOWSKI e SCOTT, 2008). Assim, tal enfoque avança na ideia de que há uma inseparabilidade inerente entre o técnico e o social.

No que diz respeito a uma agenda de pesquisas futuras neste campo, Orlikowski e Scott (2008) apontam um desafio importante: o desenvolvimento de formas de pensar e falar sobre os mundos sociais e materiais como inseparáveis, como constitutivamente emaranhados. Por fim, os autores acreditam que a perspectiva sociomaterial pode oferecer uma abordagem promissora para reconsiderar o status da tecnologia na pesquisa organizacional, e dessa forma aumentar o entendimento das práticas na vida organizacional contemporânea.

$\mathrm{Na}$ mesma linha de pensamento de Orlikowski e Scott encontram-se Leonardi, Nardi, e Kallinikos (2012), que asseveram que um dos temas mais populares, mais citados, mais debatidos, e mais criticados nas áreas de sistemas e de gestão da informação é o tema da sociomaterialidade. Segundo os autores, em geral, os trabalhos que escrevem sobre sociomaterialidade iniciam com uma descrição do termo sociomaterial - uma fusão deliberada das palavras social e material - toda materialidade é social na medida em que foi criada através de processos sociais e que é interpretada e utilizada em contextos sociais, e toda ação social é possível por causa de alguma materialidade.

Leonardi (2011) argumenta, também, que as fronteiras entre o social e o material não são pré-determinadas; são promulgadas na prática do próprio trabalho. A esse respeito, vale a pena destacar que a prática aparece constantemente com um destaque especial nos artigos envolvendo o tema da sociomaterialidade. 


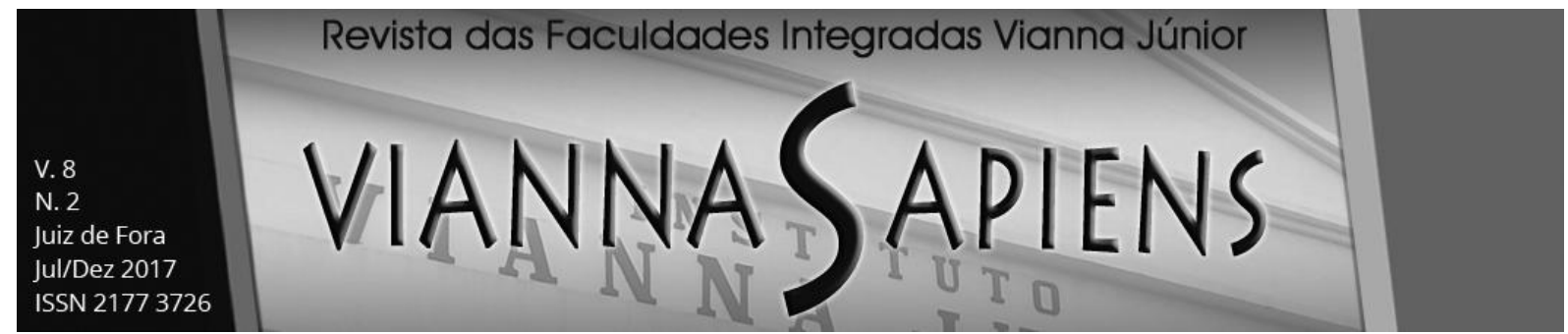

Leonardi, Nardi, e Kallinikos (2012) indicam que por muitos anos, os estudiosos organizacionais, interessados em mudanças tecnológicas (operacionalizando tecnologia como os processos de trabalho realizados em conjunto com máquinas), realizavam pesquisas em nível macro (tendo a organização como a unidade de análise), com o objetivo de investigar os efeitos que a mudança de tecnologia havia promovido na estrutura formal de determinadas organizações. Na medida em que os achados desta geração de pesquisas ofereciam um número cada vez menor de insights interessantes, uma nova onda de investigação em nível micro (com o indivíduo ou grupo como unidade de análise) começou a explorar como as pessoas nas organizações usavam as tecnologias para realizar seu trabalho.

Uma das dificuldades de desenvolvimento do tema reside no fato de que vários pesquisadores da área de organizações não se consideram estudiosos de tecnologia. Nessa medida, a ação natural de ignorar o papel da tecnologia nos processos organizacionais específicos é também agravada pelo fato de que as novas tecnologias mudam com frequência e o estudo desses aspectos requer o contínuo aprendizado sobre as mudanças tecnológicas (LEONARDI, NARDI e KALLINIKOS, 2012).

Leonardi, Nardi, e Kallinikos (2012) apresentam três conceitos que podem ajudar a entender melhor o entrelaçamento entre o material e o social: materialidade, sociomaterialidade e sistemas sociotécnicos. Em relação à materialidade, os autores utilizam um exemplo interessante, ao sugerir que se considere uma tecnologia física, como um martelo. Seria relativamente fácil de isolar e descrever um conjunto de propriedades a ele inerentes. Por exemplo, pode-se apontar para o aço da qual a cabeça foi formada, a fibra de vidro que foi moldada no punho, e a borracha que foi colocada no topo da fibra de vidro. Pode-se facilmente dizer que os materiais a partir dos quais o martelo foi feito eram de aço, fibra de vidro e borracha. Mas, quando se passa da esfera do físico para o digital, torna-se muito mais difícil isolar os materiais dos quais uma tecnologia é construída. Assim, perguntam os autores: quais são os 


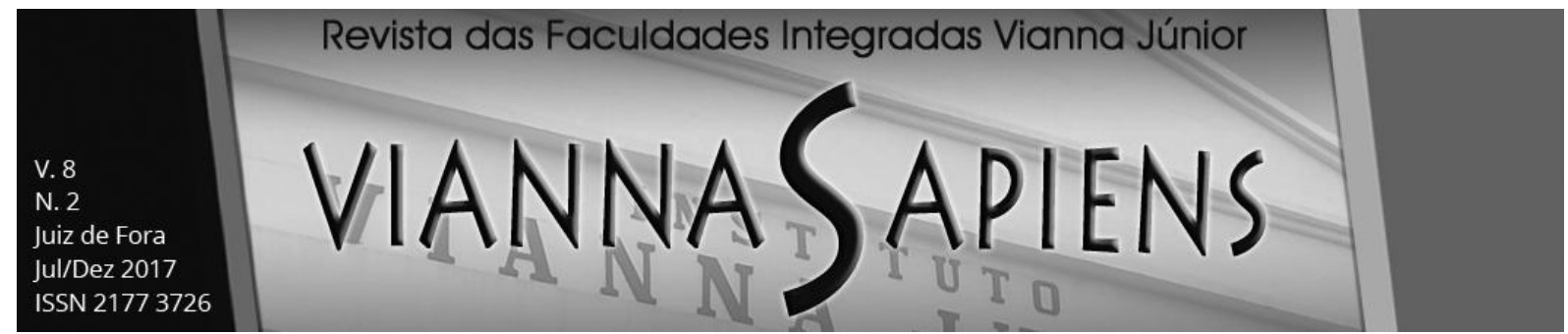

materiais que compõem um documento do Microsoft Word? Quais são os materiais que formam as ferramentas de mídias sociais? A maioria dos artefatos de tecnologia da informação, como programas de computador e várias aplicações de software não tem "fisicalidade", concluem.

Em suma, segundo Leonardi, Nardi, e Kallinikos (2012), a materialidade pode ser útil aos pesquisadores por: a) dirigir a atenção dos pesquisadores para as propriedades intrínsecas aos artefatos tecnológicos; b) lembrar que essas propriedades são fixas, pelo menos por um curto período de tempo, e; c) incentivar a exploração não apenas dos meios pelos quais as propriedades intrínsecas se tornam fixas, mas também como esse fenômeno afeta o que as pessoas consideram ser importante para o seu trabalho. Então, há de se concordar com Leonardi, Nardi, e Kallinikos (2012), que a seguinte formulação é pertinente: por que simplesmente não usar o termo "Tecnologia" em vez de "Materialidade"? Para responder a essa pergunta, os autores se voltam para outro termo: "sociomaterialidade".

Os teóricos organizacionais defendem um entrelaçamento do social com a materialidade da tecnologia, mas focam, principalmente, na forma como um novo artefato funde-se com um sistema social da organização durante a sua adoção e utilização. Contudo, não abordam o entrelaçamento de fato (LEONARDI, NARDI, e KALLINIKOS, 2012). Os autores consideram também que, falar de sociomaterialidade é reconhecer e manter sempre presente à mente que a materialidade funciona como um elemento constitutivo do mundo social, e viceversa.

Leonardi (2011) oferece uma teoria sobre como o social e o material tornamse enredados. Sugere que as agências humanas coordenadas (agência social) e as coisas que a materialidade de uma tecnologia permite às pessoas fazerem (agência material) tornam-se interligadas em sequências que produzem os fenômenos empíricos que chamamos de "tecnologias", por um lado, e "organizações", por outro. A agência humana - outro elemento citado por Leonardi (2011) na teoria da sociomaterialidade - geralmente definida como a capacidade de elaborar e realizar 


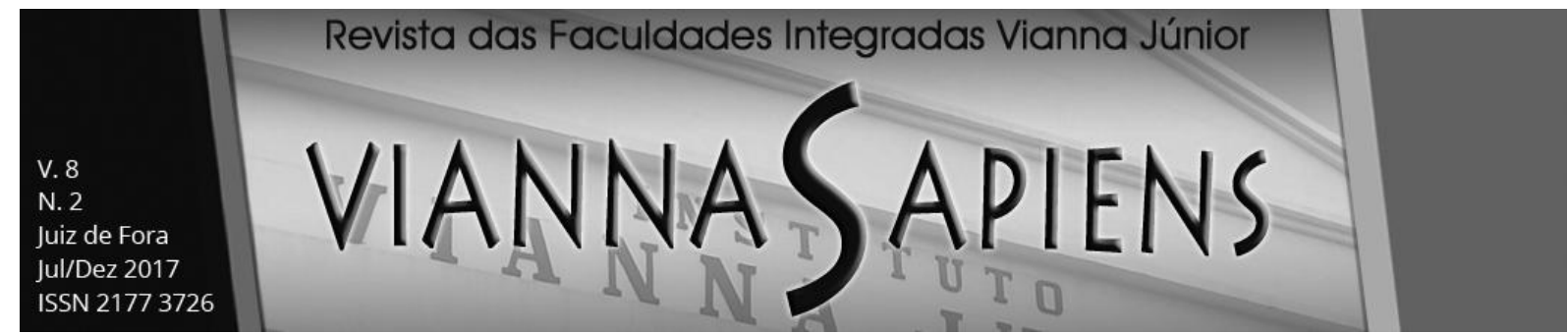

objetivos individuais (EMIRBAYER e MISCHE, 1998). A perspectiva da agência humana sugere que trabalho das pessoas não é determinado pelas tecnologias empregadas. Pesquisas mostram que, mesmo diante das tecnologias aparentemente mais restritivas, agentes humanos podem exercer a sua discrição para moldar os efeitos que essas tecnologias acarretam no seu trabalho (BOUDREAU e ROBEY, 2005).

\subsection{Artefatos de Tecnologia da Informação}

Leonardi, Nardi, e Kallinikos (2012) consideram que os SI (Sistemas de Informação) são comumente vistos como dispositivos representativos da realidade mediante a entrada de dados, processamento e saída de informação. A abordagem sociomaterial, permite que o conceito de tecnologia da informação seja tratado em uma nova perspectiva, definido como emaranhamento sociotécnico de artefato de TI, práticas de trabalho, usuários e desenvolvedores.

A tecnologia da informação se caracteriza como um importante elemento associado ao trabalho nos mais diversos níveis organizacionais, como chão de fábrica, aplicações comerciais, na integração de processos junto aos clientes, ou mesmo no mercado mundial (MANSELL et al, 2007).

Os artefatos de $\mathrm{TI}$ constituem uma parte significativa da tecnologia da informação. Eles são especificados e criados com o objetivo de apoiar as atividades humanas nos mais diversos cenários. Quanto à aplicação, os artefatos podem ser utilizados em rotinas organizacionais ou individuais; também podem ser encontrados nos mais variados formatos, e as possibilidades de suas aplicações também se tornam amplamente distintas (ZANG et al, 2011).

Uma melhor compreensão das implicações do uso dos artefatos de TI pode ajudar as organizações a avaliar melhor seus sistemas de informação assim como 


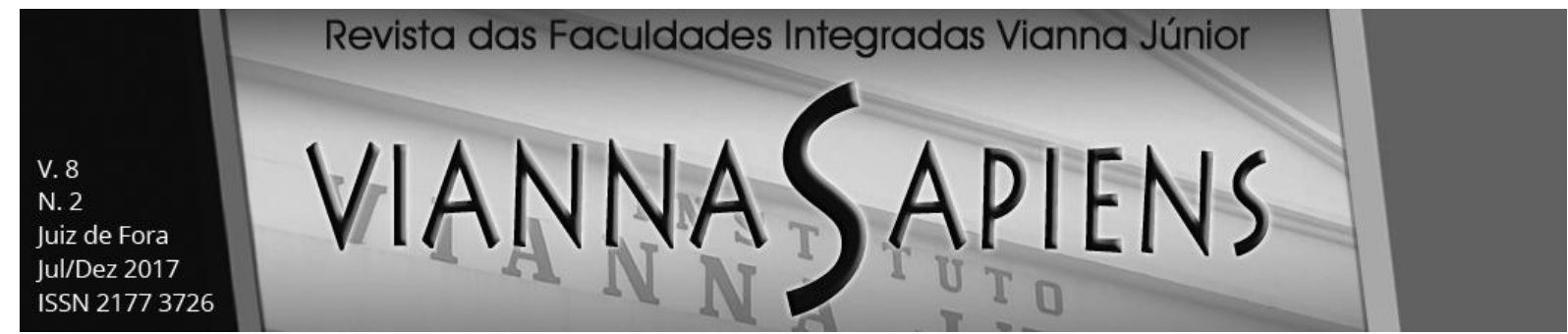

sua influência nas rotinas organizacionais, de modo que possa oferecer novos insigths para o entendimento do relacionamento entre o social e o material, explorando as diferentes visões do conceito (ORLIKOWSKI e SCOTT, 2008).

Zang et al (2011) asseveram cinco elementos essenciais para a formação dos artefatos de TI: hardware, software e sistema operacional, software aplicativo, o conteúdo do aplicativo, e artefatos auxiliares.

Zang et al (2011) apontam para uma frequente discordância entre pesquisadores que atuam na área de Sistemas de Informação, em relação ao fato de se caracterizar uma área de conhecimento em particular, ou se pertencem a outras áreas de conhecimento já existentes, como por exemplo, gestão, engenharia ou comunicações. Os autores também salientam o fato dos pesquisadores, em geral, se interessarem mais pelo fenômeno no contexto onde o artefato de TI está inserido, do que pelo artefato propriamente dito. Em outras palavras, um sistema ERP (Enterprise Resource Planning) pode trazer estudos sobre o comportamento das pessoas, processos organizacionais e capacidades dinâmicas da organização, mas sem revelar detalhes sobre a tecnologia envolvida no sistema.

Segundo Zang et al (2011), artefatos de TI podem assumir diversas configurações, a partir de regras de negócio e procedimentos definidos no âmbito das organizações onde operam. Software e sistemas de informação estão entre os tipos mais comuns de artefatos de TI. Caminhando na direção de um marco teórico acerca dos artefatos de $\mathrm{TI}$, os autores retratam um quadro consolidado, visando melhor entendimento dos conceitos extraídos da literatura sobre os artefatos de TI, demonstrados no quadro 1. 


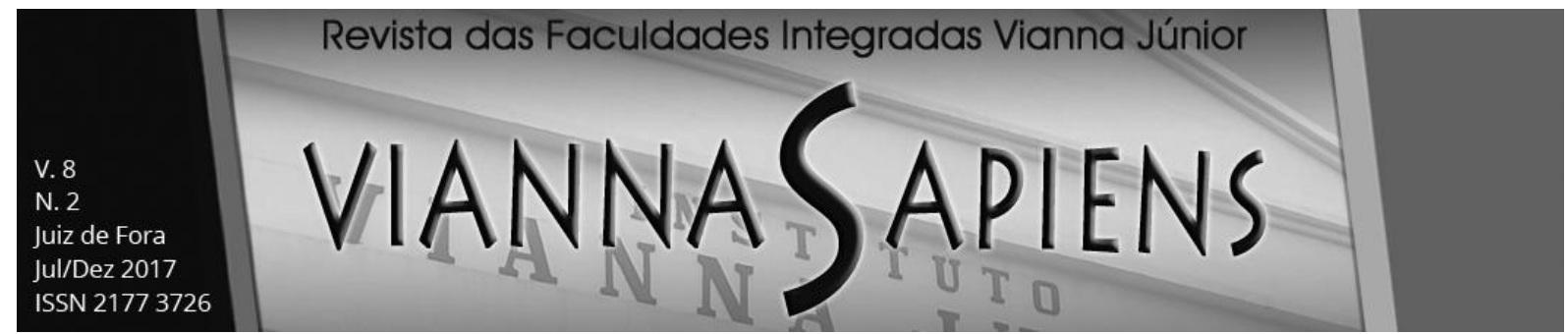

\begin{tabular}{|c|c|}
\hline \multicolumn{2}{|r|}{ Quadro1. Noções populares de Artefatos de TI } \\
\hline Fonte & Descrição \\
\hline $\begin{array}{l}\text { Orlikowski e lacono } \\
(2001, \text { p. 121)) }\end{array}$ & $\begin{array}{l}\text { Pacotes de propriedades materiais e culturais } \\
\text { embalados em alguma forma socialmente reconhecível como } \\
\text { hardware e/ou software }\end{array}$ \\
\hline $\begin{array}{l}\text { Benbasat e Zmud } \\
(2003, . \text { 186)) }\end{array}$ & $\begin{array}{l}\text { A aplicação de TI para permitir ou apoiar alguma(s) } \\
\text { tarefa(s) incorporada(s) dentro de uma(s) estrutura(s), que em si } \\
\text { é incorporada(s) dentro de um contexto(s)", na qual a sua } \\
\text { design de hardware/software "encapsula as estruturas, rotinas, } \\
\text { normas e valores implícitos nos contextos em que o artefato } \\
\text { está inserido }\end{array}$ \\
\hline $\begin{array}{c}\text { King } \\
(2004, \text { p. 541)) }\end{array}$ & $\begin{array}{l}\text { Processamento sistemático de informações na empresa } \\
\text { humana }\end{array}$ \\
\hline $\begin{array}{l}\text { Hevner et al. } \\
(2004, \text { p. } 77))\end{array}$ & $\begin{array}{l}\text { Construtos (vocabulário e símbolos), modelos } \\
\text { (abstrações e representações), métodos (algoritmos e práticas), } \\
\text { e instâncias (implementadas e protótipos de sistemas" }\end{array}$ \\
\hline $\begin{array}{l}\text { Agarwal e Lucas } \\
(2005, \text { p. 394)) }\end{array}$ & $\begin{array}{l}\text { "A integração do processamento lógico encontrado em } \\
\text { computadores com armazenamento massivo de bancos de } \\
\text { dados e conectividade de redes de comunicação", desde que } \\
\text { "inclua infra-estrutura de TI, inovações com tecnologia, e } \\
\text { especialmente, a Internet }\end{array}$ \\
\hline
\end{tabular}

Fonte: Zang et al. (2011)

A definição de Tecnologia da Informação trazida por Orlikowski e lacono (2001) discorre que a mesma está além das ferramentas tecnológicas vigentes no ambiente organizacional. Segundo as autoras, as conceituações relacionadas à tecnologia da informação estão divididas em cinco categorias distintas: ferramenta, proxy, conjunto, computacional e nominal. Cada uma das categorias é explicada a seguir:

- Ferramenta - o artefato está ligado à sua construção interna, independente do contexto organizacional ou social onde está inserido. Os estudos nesse sentido apontam para o desempenho e a capacidade de processamento. 


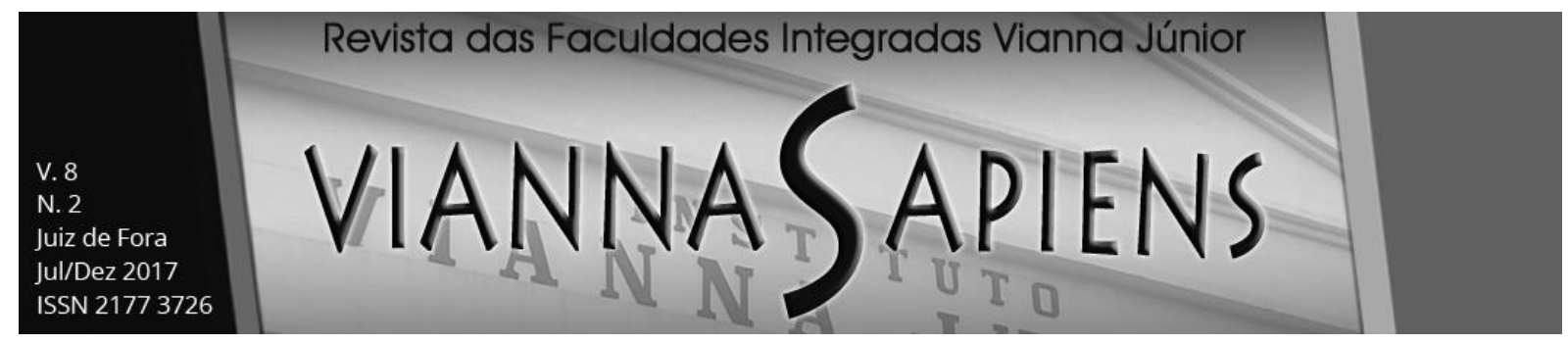

- Proxy - possui foco nos aspectos considerados fundamentais da tecnologia da informação, sua propriedade ou valor. São estudados os valores investidos e, tecnologia e as mudanças ocorridas são acompanhadas ao longo do tempo para compreender o verdadeiro papel desempenhado pela tecnologia nas organizações.

- Conjunto - embora o artefato de TI possa ter um papel principal na maneira como a tecnologia é percebida nas organizações, trata-se também de um elemento que faz parte de um pacote maior, destinado a alguma atividade socioeconômica.

- Computacional - importa com a capacidade da tecnologia em manipular, armazenar, recuperar e transmitir informações, ligadas geralmente a algoritmos e modelos computacionais.

- Nominal - ocupa-se com os nomes e atribuições aos artefatos de TI, que podem surgir como "tecnologia da informação", "sistema de informação", ou "computador", onde muitas vezes podem representar diferentes conceitos.

Orlikowski e lacono (2001) destacam, ainda, que existem várias maneiras de como teorizar os artefatos de TI, baseadas em cinco princípios:

- Não são naturais, neutros, nem universais; são implicados na ação e efeito, pois são desenvolvidos e utilizados por pessoas, e moldados pelos valores e interesses de cada um.

- São incorporados em algum tempo e lugar, e não em sua materialidade iognorada.

- São normalmente feitos sob uma diversidade de componentes fragmentados, baseados no trabalho em conjunto. 


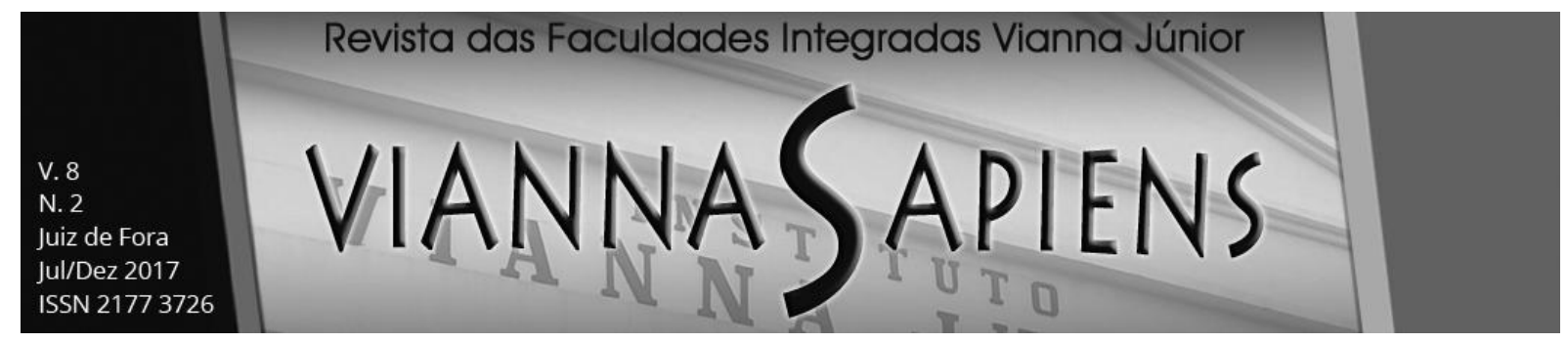

- Não são independentes, mas surgem a partir das práticas sociais, que implicam em mudanças ao longo do tempo.

- São dinâmicos, uma vez que são reinventados, e incorporam constantemente novas características.

Por sua vez, Zang et al. (2011) entendem que o contexto onde o artefato de TI é implementado se torna um componente importante para pesquisas na área, pois devido às tecnologias móveis podem ser utilizados, com relativa frequencia, fora do seu local de trabalho.

\subsection{Rotinas Organizacionais}

Para Pentland e Feldman (2005:795), as rotinas são definidas como "ações repetitivas, com padrão reconhecível de ações interdependentes, envolvendo múltiplos atores". Os autores ainda apontam para a oportunidade de pesquisa das rotinas organizacionais como elementos fundamentais para o entendimento das organizações, pois envolvem seus aspectos ostensivos, performativos, o poder de agência dos indivíduos e a relação com os artefatos.

Pentland e Feldman (2005) também apontam para um papel de estabilidade organizacional que pode ser empregada pela rotina, quando esta é observada à distância, ao longo do tempo. Por outro lado, a rotina também pode indicar uma condição de mudança contínua, pautada em uma visão de flexibilidade e ação dos agentes que realizam a rotina.

O aspecto performativo representa as "ações específicas, por pessoas específicas, em locais e momentos específicos", enquanto que o aspecto ostensivo constitui-se da "definição ou princípio da rotina" (PENTLAND e FELDMAN, 2005:796). Desta forma, o aspecto ostensivo está relacionado à estrutura geral da 


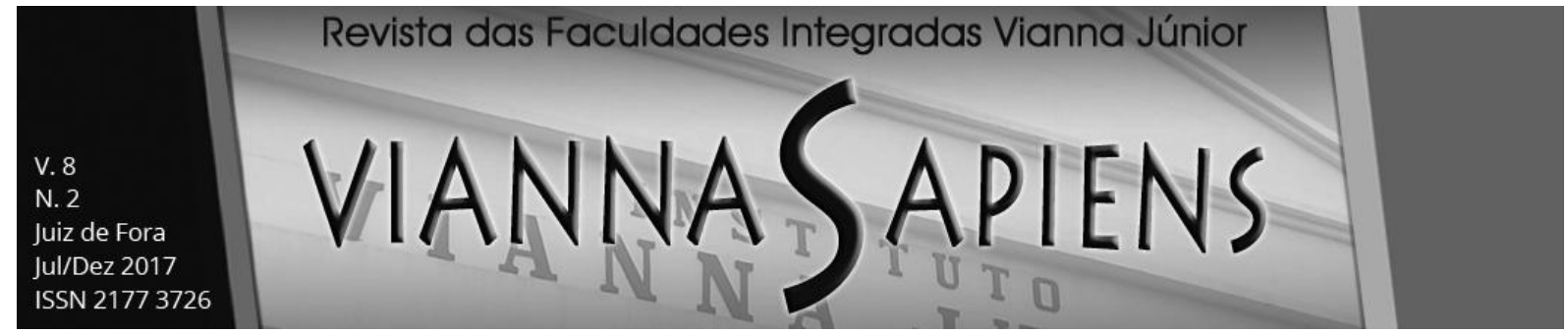

rotina, enquanto o performativo é a ação realizada na rotina. Além disso, os artefatos são tratados como itens fundamentais das rotinas organizacionais, se apresentando por meio de relatórios e informações (aspecto performativo), ou regras e procedimentos formais (aspecto ostensivo), ilustrados na figura 01.

Figura 01 - Rotinas organizacionais como sistemas generativos

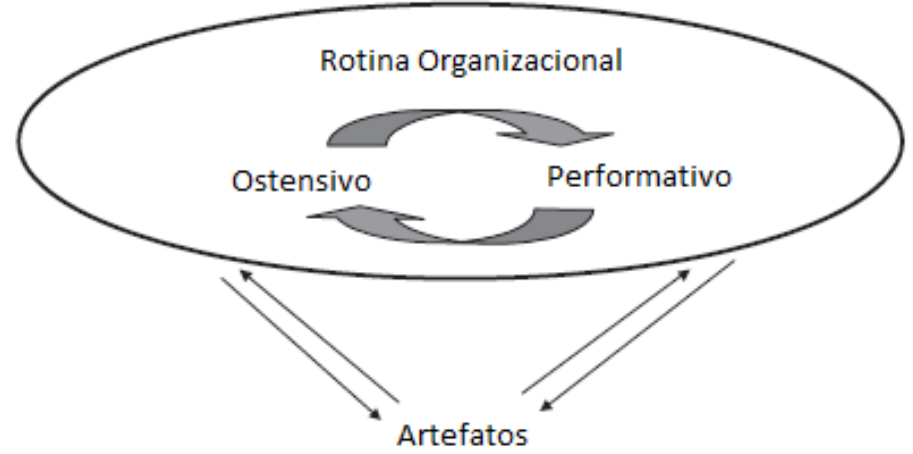

Fonte: Pentland e Feldman (2003)

Uma rotina organizational se constitui de duas partes relacionadas, onde uma parte se baseia na ideia abstrata da rotina (ostensivo), enquanto a outra parte consiste em suas performances, realizadas por pessoas, em momentos específicos, por meio de tarefas coordenadas (PENTLAND e FELDMAN, 2005). O pleno entendimento das relações existentes entre estes dois aspectos (ostensivo e performativo) pode despertar para o potencial de estudos das rotinas como fonte de mudança organizacional. Outro ponto importante relatado por Pentland e Feldman, consiste no fato de que os indivíduos podem influenciar as rotinas, por meio de sua ação no dia-a-dia, para alcançar um resultado desejado.

Pentland e Feldman (2003) apontam também para o cuidado, no sentido de lidar com os dois aspectos das rotinas como elementos totalmente entrelaçados, eliminando possíveis diferenças entre eles. Assim, em uma rotina organizacional, os artefatos podem definir e influenciar tanto os aspectos ostensivo quanto os aspectos performativos. Artefatos, por sua vez, podem assumir formas diferentes, a partir de 


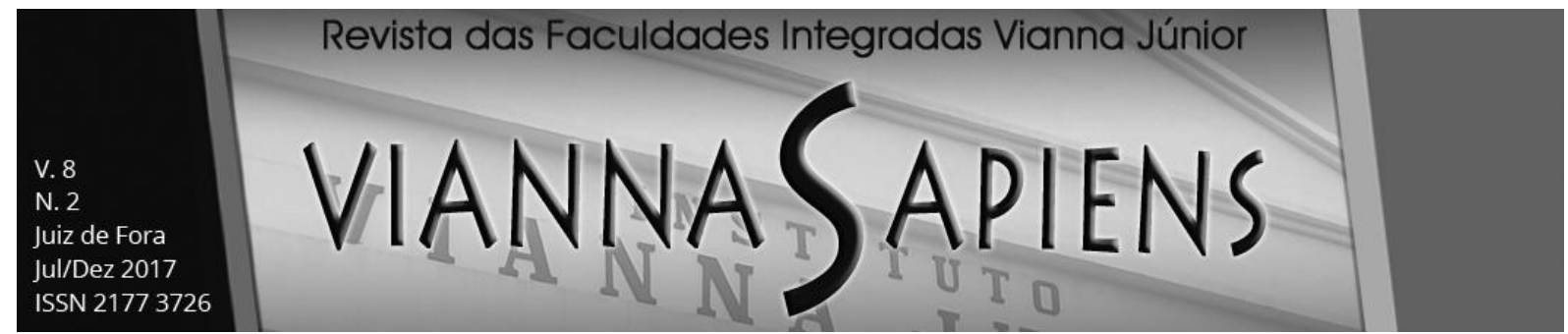

regras de negócio e procedimentos, inerentes ao contexto onde se encontram. Como exemplo, temos computadores e bancos de dados, que suportam a tomada de decisões, que podem compor uma importante maneira de coleta de dados sobre as rotinas (PENTLAND e FELDMAN, 2003).

Por outro lado, na visão de Parmigiani e Howard-Grenville (2011), os artefatos exercem pouca influência, em geral, sobre a maneira como as rotinas são executadas. Entretanto, essa afirmação é questionada por D’Adderio (2011), a qual defende o artefato ocupando uma posição central na rotina. Na visão de Parmigiani e Howard-Grenville (2011), o conceito de rotina organizacional pode ser visto a partir de duas compreensões distintas: padrões estáveis versus mudança contínua. Também retratam que as rotinas podem ser transferidas entre organizações, assim como os genes se difundem no interior de uma população. Como exemplo, trazem a comparação entre empresas franqueadas e não franqueadas, sugerindo que as primeiras utilizam as rotinas padronizadas de forma mais ampla.

Howard-Grenville (2005) destaca que, apesar de serem consideradas estáveis e flexíveis, as rotinas estão sendo tratadas como elementos que podem proporcionar uma mudança endógena nas organizações, ou seja, de dentro para fora. Uma vez que as rotinas são criadas para atingir uma determinada performance deveriam, a princípio, se encaminhar para a estabilidade. Alguns tipos de organizações, como montadoras de automóveis, apresentam menos espaço para flexibilização das rotinas do que outros tipos de organização, como empresas de tecnologia, por exemplo. Assim, as rotinas podem emergir a partir da forma como o trabalho é organizado, das características da organização, e dos modelos cognitivos dos participantes.

Assim, o estudo das rotinas organizacionais como um sistema, pode propor diferentes oportunidades de trabalhos para os pesquisadores. Por um lado, pode-se inicialmente desconsiderar a estrutura interna da rotina e trata-la como uma "caixa preta". Em outra vertente, pode-se aprofundar na complexidade das interações entre 


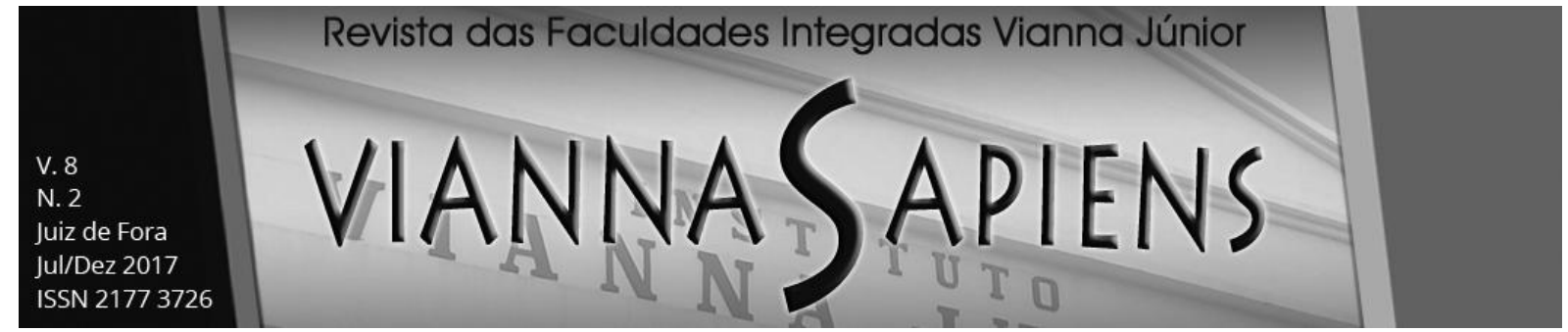

os aspectos ostensivo, performativo e seus artefatos (PENTLAND e FELDMAN, 2003).

\section{A BUSCA PELO ENTRELAÇAMENTO: uma proposição}

Partindo-se do princípio de que a sociomaterialidade pode ser expressa e encontrada nas rotinas organizacionais, espaço de aplicação de diversas tecnologias, e de que os artefatos podem representar a tecnologia empregada com vistas à melhoria das práticas organizacionais, buscou-se levantar o estado da arte a respeito da problematização desses temas no Brasil. Para tanto, empreendeu-se uma pesquisa na base de publicações da Anpad (http://www.anpad.org.br/ anpad/) por entender que essa entidade representa o fórum máximo de discussão sobre os temas abordados neste trabalho e sobre os Estudos Organizacionais no Brasil. Também foram considerados os últimos dez anos (2004 a 2014).

As palavras-chave utilizadas inicialmente foram "tecnologia da informação", "rotina", "sociomaterial" e "artefato". A primeira pesquisa, com "tecnologia da informação" retornou um total de cento e vinte e três artigos. Após análise individual, foram selecionados quarenta e três, que circunscreviam aos aspectos organizacionais e gerencias da $\mathrm{TI}$, mais adequadas aos objetivos deste trabalho. Pelo mesmo motivo, a palavra "rotina" foi refinada para "rotinas organizacionais" e retornou dois artigos, "sociomaterial" não retornou nenhum artigo, e "artefato" retornou onze artigos, sendo somente um ligado à gestão da informação. Um breve resumo com os principais pontos dos artigos pesquisados apresenta-se nos quadros 2,3 e 4: 


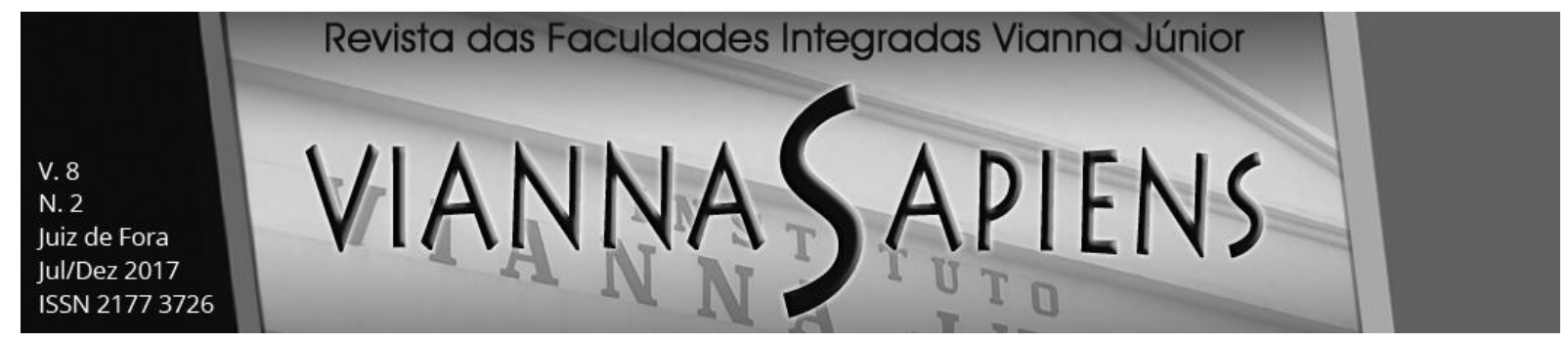

Quadro 2. Pesquisas sobre tecnologia da informação

\begin{tabular}{|c|c|c|c|c|}
\hline Autores & Objetivos do Estudo & Metodologia & Principais Resultados & $\begin{array}{l}\text { Concei- } \\
\text { tos } \\
\text { Encon- } \\
\text { trados }\end{array}$ \\
\hline $\begin{array}{l}\text { Amaral, } \\
\text { Ziviani, De } \\
\text { Muylder,Parr } \\
\text { eiras, } \\
\text { Neves, } \\
\text { Kilimnik } \\
(2014)\end{array}$ & $\begin{array}{l}\text { Avaliar a relação } \\
\text { existente entre o } \\
\text { desempenho } \\
\text { organizacional, a } \\
\text { governança de TI e a } \\
\text { gestão de processos } \\
\text { em projetos }\end{array}$ & $\begin{array}{l}\text { Análise de } \\
\text { equações } \\
\text { estruturais }\end{array}$ & Um novo modelo validado & $\mathrm{TI}$ \\
\hline $\begin{array}{l}\text { Wiedenhöft, } \\
\text { Luciano, } \\
\text { Testa (2013) }\end{array}$ & $\begin{array}{l}\text { Compreender como } \\
\text { ocorre a decisão } \\
\text { acerca da adoção de } \\
\text { mecanismos de GTI } \\
\text { em termos do } \\
\text { processo }\end{array}$ & $\begin{array}{l}\text { Entrevistas } \\
\text { em } \\
\text { profundidade }\end{array}$ & $\begin{array}{l}\text { A adoção da GTI ocorre muito mais } \\
\text { pela legitimação de seus } \\
\text { mecanismos do que com base em } \\
\text { elementos formais internos à } \\
\text { organização. }\end{array}$ & $\mathrm{TI}$ \\
\hline $\begin{array}{l}\text { Diehl, Testa, } \\
\text { Luciano } \\
\text { (2012) }\end{array}$ & $\begin{array}{l}\text { Analisar como os } \\
\text { usuários corporativos } \\
\text { se adaptam às } \\
\text { mudanças de TI numa } \\
\text { organização }\end{array}$ & $\begin{array}{l}\text { Estudo de } \\
\text { caso }\end{array}$ & $\begin{array}{l}\text { Resultados corroboraram o } \\
\text { modelo, indicando que a influência } \\
\text { social e emoções têm papel } \\
\text { fundamental na adaptação, e que } \\
\text { resistência pode culminar }\end{array}$ & $\mathrm{TI}$ \\
\hline $\begin{array}{l}\text { Rasera, } \\
\text { Cherobim } \\
(2011))\end{array}$ & $\begin{array}{l}\text { Verificar a existência } \\
\text { de associações entre } \\
\text { diversos aspectos da } \\
\text { GTI e indicadores de } \\
\text { inovação }\end{array}$ & $\begin{array}{l}\text { Survey e teste } \\
\text { de Mann- } \\
\text { Whitney }\end{array}$ & $\begin{array}{l}\text { Diversos aspectos da GTI estão } \\
\text { associados significativamente com } \\
\text { indicadores de inovação, com } \\
\text { exceção da entrega de valor }\end{array}$ & $\mathrm{TI}$ \\
\hline $\begin{array}{l}\text { Santilli, } \\
\text { Luciano, } \\
\text { Testa (2011) }\end{array}$ & $\begin{array}{l}\text { Analisar como a } \\
\text { Governança de TI é } \\
\text { afetada pela Gestão } \\
\text { de Contratos de TI em } \\
\text { um contexto de } \\
\text { terceirização }\end{array}$ & $\begin{array}{l}\text { Pesquisa } \\
\text { qualitativa } \\
\text { exploratória } \\
\text { em um estudo } \\
\text { de caso }\end{array}$ & $\begin{array}{l}\text { Gestão de Contratos de TI afeta a } \\
\text { Governança de TI através de } \\
\text { normas e procedimentos técnicos }\end{array}$ & $\mathrm{TI}$ \\
\hline $\begin{array}{l}\text { Silva, } \\
\text { Ribeiro } \\
\text { (2011) }\end{array}$ & $\begin{array}{l}\text { Observar as } \\
\text { diferentes percepções } \\
\text { da presença de GTI } \\
\text { de um departamento } \\
\text { de tecnologia da } \\
\text { informação de um } \\
\text { Tribunal de Justiça } \\
\text { Estadual }\end{array}$ & $\begin{array}{l}\text { Entrevistas } \\
\text { semiestrutura- } \\
\text { das e } \\
\text { observações } \\
\text { participantes }\end{array}$ & $\begin{array}{l}\text { Distanciamento no entendimento } \\
\text { da GTI entre os gestores } \\
\text { responsáveis pela direção } \\
\text { estratégica e a equipe operacional }\end{array}$ & $\begin{array}{l}\text { TI, } \\
\text { Artefato }\end{array}$ \\
\hline
\end{tabular}




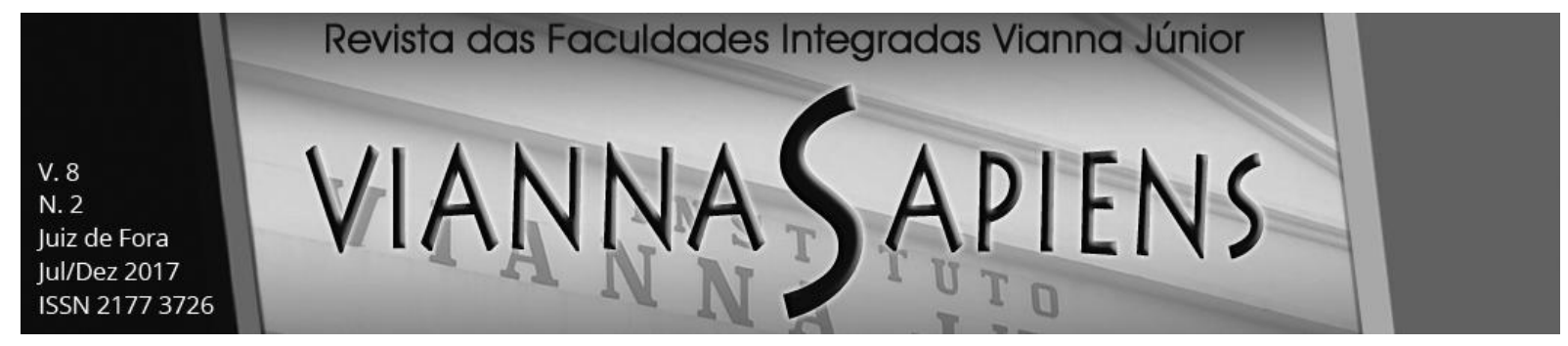

\begin{tabular}{|c|c|c|c|c|}
\hline $\begin{array}{l}\text { Pereira, } \\
\text { Martins, } \\
\text { Maia (2011) }\end{array}$ & $\begin{array}{l}\text { Analisar como a } \\
\text { substituição de um } \\
\text { sistema de } \\
\text { informação gerencial } \\
\text { (SIG) pode impactar } \\
\text { na aceitação de um } \\
\text { novo sistema pelo } \\
\text { usuário }\end{array}$ & $\begin{array}{l}\text { Estudo de } \\
\text { caso }\end{array}$ & $\begin{array}{l}\text { A substituição de um sistema de } \\
\text { informação gerencial } \\
\text { (SIG) pode impactar na aceitação } \\
\text { do novo sistema pelo usuário, a } \\
\text { depender principalmente do seu } \\
\text { grau de ludicidade }\end{array}$ & $\mathrm{TI}$ \\
\hline $\begin{array}{l}\text { Silva, } \\
\text { Dornelas } \\
\text { (2011) }\end{array}$ & \begin{tabular}{|l|} 
Analisar as \\
perspectivas do \\
alinhamento \\
estratégico entre \\
estratégia de \\
negócios e tecnologia \\
da informação em \\
empresas de software
\end{tabular} & $\begin{array}{l}\text { Survey } e \\
\text { análise de } \\
\text { cluster }\end{array}$ & $\begin{array}{l}\text { As empresas analisadas são } \\
\text { semelhantes, e preocupam-se em } \\
\text { ter uma estratégia de negócio } \\
\text { explicitamente definida, mas com } \\
\text { baixo nível de informatização }\end{array}$ & $\mathrm{TI}$ \\
\hline $\begin{array}{l}\text { Sgarbi, } \\
\text { Costa, } \\
\text { Farias, } \\
\text { Amorim, } \\
\text { Cândido } \\
\text { (2010) }\end{array}$ & $\begin{array}{l}\text { Analisar como os } \\
\text { aspectos da } \\
\text { capacidade de } \\
\text { inovação do APL de } \\
\text { TIC influenciam a sua } \\
\text { competitividade } \\
\text { sistêmica }\end{array}$ & Survey & $\begin{array}{l}\text { O APL de } \\
\text { TIC estudado encontra-se em um } \\
\text { nível de alerta, fragilidades } \\
\text { identificadas }\end{array}$ & $\mathrm{TI}$ \\
\hline $\begin{array}{l}\text { Amaro } \\
(2010)\end{array}$ & $\begin{array}{l}\text { Analisar a evolução } \\
\text { do emprego da GTI } \\
\text { na Marinha do Brasil }\end{array}$ & $\begin{array}{l}\text { Estudo de } \\
\text { caso }\end{array}$ & $\begin{array}{l}\text { A implantação da GTI apresenta } \\
\text { uma série de desafios, conflitos e } \\
\text { dificuldades }\end{array}$ & $\mathrm{TI}$ \\
\hline $\begin{array}{l}\text { Morais, } \\
\text { Tavares } \\
(2010)\end{array}$ & $\begin{array}{l}\text { Analisar como a } \\
\text { tecnologia da } \\
\text { informação vem } \\
\text { sendo utilizada para } \\
\text { auxiliar a gestão da } \\
\text { cadeia de } \\
\text { suprimentos (GCS) }\end{array}$ & Survey & $\begin{array}{l}\text { Uso incipiente de instrumentos } \\
\text { específicos de TI na GCS entre os } \\
\text { fornecedores locais }\end{array}$ & $\mathrm{TI}$ \\
\hline $\begin{array}{l}\text { Scheeren, } \\
\text { Filho (2010) }\end{array}$ & $\begin{array}{l}\text { Analisar um } \\
\text { mecanismo de } \\
\text { governança de TI } \\
\text { utilizado por uma } \\
\text { organização }\end{array}$ & $\begin{array}{l}\text { Estudo de } \\
\text { caso }\end{array}$ & $\begin{array}{l}\text { Evidência de ganhos da } \\
\text { implantação do modelo de GTI } \\
\text { para a organização }\end{array}$ & $\mathrm{TI}$ \\
\hline $\begin{array}{l}\text { Dornelas, } \\
\text { Baptista, } \\
\text { Junior, } \\
\text { Freitas, } \\
\text { Costa (2010) }\end{array}$ & $\begin{array}{l}\text { Compreender o } \\
\text { processo de } \\
\text { alinhamento } \\
\text { estratégico de (TI) de } \\
\text { uma empresa do } \\
\text { setor siderúrgico } \\
\text { brasileiro }\end{array}$ & Entrevistas & $\begin{array}{l}\text { Apontam para uma tendência de } \\
\text { alinhamento da práxis da } \\
\text { organização com os elementos do } \\
\text { modelo teórico escolhido }\end{array}$ & $\begin{array}{l}\text { Tl, } \\
\text { Rotinas }\end{array}$ \\
\hline
\end{tabular}




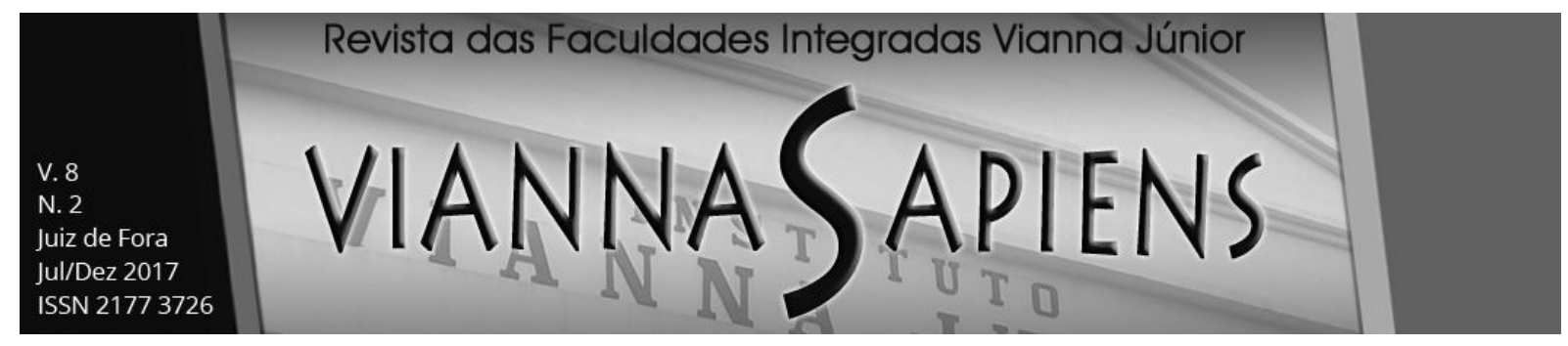

\begin{tabular}{|c|c|c|c|c|}
\hline $\begin{array}{l}\text { Rezende, } \\
\text { Leite (2009) }\end{array}$ & \begin{tabular}{|l|} 
Analisar o \\
alinhamento, as \\
relações e \\
contribuições da TI \\
nos planos e \\
municipais e na \\
gestão de 110 \\
prefeituras brasileiras
\end{tabular} & Survey & $\begin{array}{l}\text { Dificuldades dos municípios na } \\
\text { organização dos dados municipais, } \\
\text { na disponibilização de informações } \\
\text { e nos planos de gestão dos } \\
\text { municípios }\end{array}$ & $\mathrm{TI}$ \\
\hline $\begin{array}{l}\text { Silva, } \\
\text { Moraes } \\
\text { (2009) }\end{array}$ & $\begin{array}{l}\text { Analisar como os } \\
\text { direcionadores do uso } \\
\text { de TI, influenciam na } \\
\text { estruturação de sua } \\
\text { governança }\end{array}$ & $\begin{array}{l}\text { Estudo de } \\
\text { caso }\end{array}$ & $\begin{array}{l}\text { Investimentos em TI influenciam } \\
\text { positivamente as decisões sobre } \\
\text { sua governança, e o contexto } \\
\text { interno não influencia diretamente } \\
\text { os aspectos das decisões sobre } \\
\text { sua governança }\end{array}$ & $\mathrm{TI}$ \\
\hline $\begin{array}{l}\text { Canuto, } \\
\text { Cherobim } \\
\text { (2009) }\end{array}$ & $\begin{array}{l}\text { Analisar a relação } \\
\text { entre os } \\
\text { investimentos em TI e } \\
\text { o grau de } \\
\text { informatização (Gl) } \\
\text { das organizações }\end{array}$ & Survey & $\begin{array}{l}\text { Hipótese corroborada do tipo de } \\
\text { investimentos em TI serem } \\
\text { diferentes em virtude do Grau de } \\
\text { Informatização }\end{array}$ & $\mathrm{TI}$ \\
\hline $\begin{array}{l}\text { Silva, } \\
\text { Dornelas } \\
\text { (2009) }\end{array}$ & $\begin{array}{l}\text { Analisar as } \\
\text { perspectivas do } \\
\text { alinhamento } \\
\text { estratégico entre } \\
\text { estratégia de } \\
\text { negócios e TI nas } \\
\text { pequenas empresas } \\
\text { de software do Porto } \\
\text { Digital }\end{array}$ & $\begin{array}{l}\text { Estudo de } \\
\text { casos } \\
\text { múltiplos }\end{array}$ & $\begin{array}{l}\text { Potencialidade da TI como } \\
\text { condutora do alinhamento } \\
\text { estratégico }\end{array}$ & $\mathrm{TI}$ \\
\hline $\begin{array}{l}\text { Rezende } \\
\text { (2008) }\end{array}$ & $\begin{array}{l}\text { Analisar a integração, } \\
\text { o alinhamento e as } \\
\text { contribuições da TI } \\
\text { nos planos municipais } \\
\text { e na gestão de } 101 \\
\text { municípios. }\end{array}$ & Survey & $\begin{array}{l}\text { Dificuldades dos municípios na } \\
\text { organização dos dados municipais, } \\
\text { na disponibilização de informações } \\
\text { e nos planejamentos para fins de } \\
\text { gestão dos municípios. }\end{array}$ & $\mathrm{TI}$ \\
\hline $\begin{array}{l}\text { Bezerra, } \\
\text { Dornelas } \\
\text { (2008) }\end{array}$ & $\begin{array}{l}\text { Analisar os impactos } \\
\text { causados pela } \\
\text { adoção da } \\
\text { terceirização não- } \\
\text { seletiva em tecnologia } \\
\text { da informação para } \\
\text { uma empresa de } \\
\text { utliities }\end{array}$ & $\begin{array}{l}\text { Estudo de } \\
\text { caso }\end{array}$ & $\begin{array}{l}\text { Os impactos apurados foram } \\
\text { significativos, indicando para uma } \\
\text { realidade fora de controle }\end{array}$ & $\mathrm{TI}$ \\
\hline $\begin{array}{l}\text { Souza, Joia } \\
\text { (2008) }\end{array}$ & $\begin{array}{l}\text { Propor uma } \\
\text { articulação entre os } \\
\text { modelos de }\end{array}$ & $\begin{array}{l}\text { Ensaio } \\
\text { Teórico }\end{array}$ & $\begin{array}{l}\text { Proposição de um modelo } \\
\text { conceitual teórico }\end{array}$ & $\mathrm{TI}$ \\
\hline
\end{tabular}




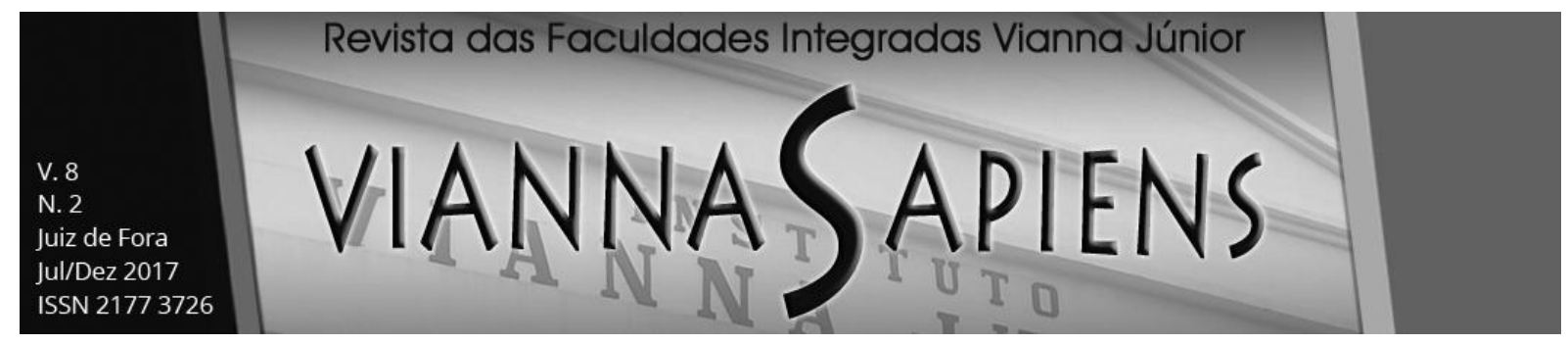

\begin{tabular}{|c|c|c|c|c|}
\hline & \begin{tabular}{|l} 
alinhamento \\
estratégico de $\mathrm{TI}$ \\
existentes, de modo a \\
integrar seus vários \\
elementos comuns, \\
propondo um modelo \\
conceitual
\end{tabular} & & & \\
\hline $\begin{array}{l}\text { Passos, } \\
\text { Ceita (2008) }\end{array}$ & $\begin{array}{l}\text { Estudar as práticas de } \\
\text { implementação de } \\
\text { projetos de Sistemas } \\
\text { de TI em empresas } \\
\text { localizadas em } \\
\text { Salvador }\end{array}$ & Survey & $\begin{array}{l}\text { As informações obtidas permitem } \\
\text { traçar um perfil daquelas práticas } \\
\text { que resultam em impactos } \\
\text { positivos nos projetos de } \mathrm{TI}\end{array}$ & $\mathrm{TI}$ \\
\hline $\begin{array}{l}\text { Araujo, } \\
\text { Carneiro } \\
\text { (2007) }\end{array}$ & $\begin{array}{l}\text { Entender qual é a } \\
\text { causa das filas nas } \\
\text { agências bancárias, } \\
\text { porque a implantação } \\
\text { de caixas eletrônicos } \\
\text { não foi suficiente }\end{array}$ & Entrevistas & $\begin{array}{l}\text { Na percepção dos entrevistados,o } \\
\text { problema das filas nos bancos } \\
\text { brasileiros é complexo e } \\
\text { transcende a capacidade de } \\
\text { gestão. }\end{array}$ & $\mathrm{TI}$ \\
\hline $\begin{array}{l}\text { Luciano, } \\
\text { Pilatti, Rech, } \\
\text { Testa (2007) }\end{array}$ & $\begin{array}{l}\text { Analisar como o } \\
\text { framework COBIT } \\
\text { pode auxiliar no } \\
\text { aprimoramento dos } \\
\text { processos de TI entre } \\
\text { a empresa } \\
\text { terceirizada e aquela } \\
\text { que terceiriza o } \\
\text { serviço }\end{array}$ & $\begin{array}{l}\text { Estudo de } \\
\text { caso }\end{array}$ & $\begin{array}{l}\text { Identificadas oportunidades de } \\
\text { melhoria nos processos estudados } \\
\text { e propostas ações que promovam } \\
\text { o uso das melhores práticas de TI, } \\
\text { de acordo com o COBIT }\end{array}$ & $\mathrm{TI}$ \\
\hline $\begin{array}{l}\text { Fumagalli, } \\
\text { Piva, Kato } \\
\text { (2007) }\end{array}$ & $\begin{array}{l}\text { Identificar e descrever } \\
\text { os impactos dos } \\
\text { investimentos em TI } \\
\text { nas diferentes áreas } \\
\text { funcionais que } \\
\text { compõem uma } \\
\text { organização } \\
\text { hospitalar }\end{array}$ & $\begin{array}{l}\text { Estudo de } \\
\text { caso }\end{array}$ & $\begin{array}{l}\text { Verificou-se que os investimentos } \\
\text { em TI na organização resultam em } \\
\text { melhor alocação de recursos; } \\
\text { melhor comunicação e fluxo de } \\
\text { informação entre áreas e aumento } \\
\text { da qualidade dos serviços }\end{array}$ & $\mathrm{TI}$ \\
\hline $\begin{array}{l}\text { Busanelo, } \\
\text { Vieira, } \\
\text { Lopes, } \\
\text { Periotto } \\
\text { (2007) }\end{array}$ & $\begin{array}{l}\text { Analisar o processo } \\
\text { de institucionalização } \\
\text { do alinhamento } \\
\text { estratégico de } \\
\text { negócios e TI em uma } \\
\text { cooperativa agrícola } \\
\text { localizada no polo de } \\
\text { Navirai-MS }\end{array}$ & $\begin{array}{l}\text { Estudo de } \\
\text { Caso }\end{array}$ & $\begin{array}{l}\text { Processo de institucionalização do } \\
\text { alinhamento estratégico de } \\
\text { negócios e a TI está em fase de } \\
\text { desenvolvimento }\end{array}$ & $\mathrm{TI}$ \\
\hline $\begin{array}{l}\text { Silva, } \\
\text { Callado }\end{array}$ & $\begin{array}{l}\text { Investigar o } \\
\text { alinhamento }\end{array}$ & Estudo de & $\begin{array}{l}\text { TI tem grande impacto nos } \\
\text { negócios da empresa objeto de }\end{array}$ & $\mathrm{Tl}$ \\
\hline
\end{tabular}




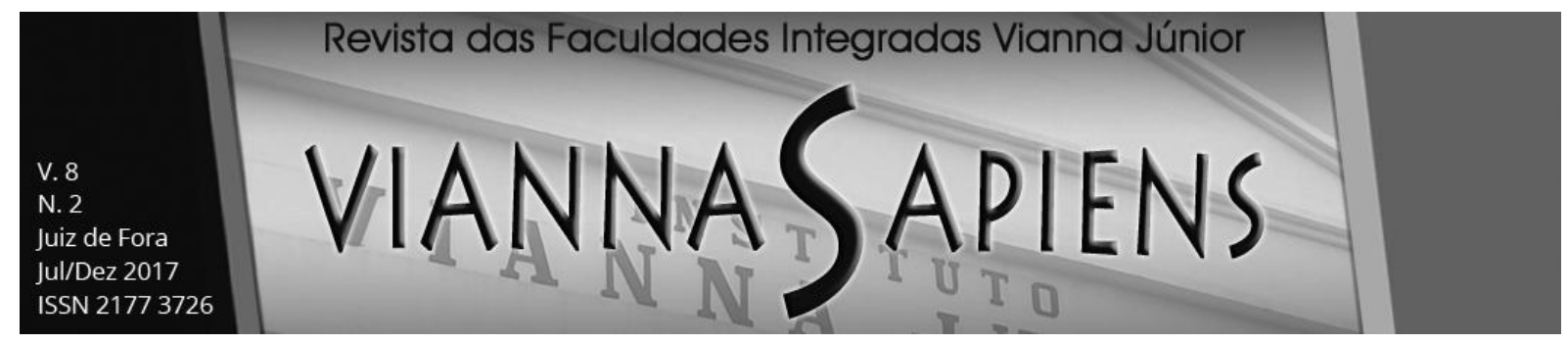

\begin{tabular}{|c|c|c|c|c|}
\hline (2007) & $\begin{array}{l}\text { estratégico entre } \\
\text { negócio e TI em uma } \\
\text { empresa de } \\
\text { desenvolvimento de } \\
\text { software }\end{array}$ & caso & $\begin{array}{l}\text { estudo e o maior desafio dela é a } \\
\text { adaptação da infraestrutura de TI } \\
\text { às capacidades organizacionais } \\
\text { para que elas estejam alinhadas } \\
\text { internamente }\end{array}$ & \\
\hline $\begin{array}{l}\text { Vicenzi, } \\
\text { Domingues, } \\
\text { Silveira } \\
\text { (2007) }\end{array}$ & $\begin{array}{l}\text { Identificar o } \\
\text { alinhamento entre a } \\
\text { Estratégia de Negócio } \\
\text { (EM) e a Estratégia } \\
\text { de Tecnologia da } \\
\text { Informação (ETI) na } \\
\text { Universidade } \\
\text { Regional de } \\
\text { Blumenau (FURB) }\end{array}$ & $\begin{array}{l}\text { Estudo de } \\
\text { caso }\end{array}$ & $\begin{array}{l}\text { FURB possui um nível médio no } \\
\text { que diz respeito à EN; não possuiu } \\
\text { ETI que a diferencie das demais } \\
\text { instituições. } \\
\text { Não possui alinhamento entre a EN } \\
\text { e a ETI }\end{array}$ & $\mathrm{TI}$ \\
\hline $\begin{array}{l}\text { Affeldt, Vanti } \\
\text { (2007) }\end{array}$ & $\begin{array}{l}\text { Analisa de forma } \\
\text { exploratória, o apoio } \\
\text { da lógica difusa para } \\
\text { o alinhamento } \\
\text { estratégico entre TI e } \\
\text { gestão dos negócios }\end{array}$ & $\begin{array}{l}\text { Estudo de } \\
\text { caso }\end{array}$ & $\begin{array}{l}\text { Resultados encontrados permitiram } \\
\text { priorizar variáveis estratégicas para } \\
\text { alinhar o binômio TIxEstratégia }\end{array}$ & $\mathrm{TI}$ \\
\hline $\begin{array}{l}\text { Santos, } \\
\text { Macedo, } \\
\text { Benac, } \\
\text { Amorim } \\
(2007)\end{array}$ & $\begin{array}{l}\text { Avaliar a performance } \\
\text { da conversão dos } \\
\text { investimentos em TI } \\
\text { de alguns bancos em } \\
\text { operação no Brasil no } \\
\text { ano de } 2003\end{array}$ & $\begin{array}{l}\text { Análise } \\
\text { Envoltória de } \\
\text { Dados (DEA) }\end{array}$ & $\begin{array}{l}\text { Resultados obtidos indicam a } \\
\text { validade da utilização da } \\
\text { metodologia para a avaliação da } \\
\text { eficiência comparativa da } \\
\text { conversão dos investimentos em } \\
\text { bancos brasileiros }\end{array}$ & $\mathrm{TI}$ \\
\hline $\begin{array}{l}\text { Pires, Kato } \\
(2007)\end{array}$ & $\begin{array}{l}\text { Medir a relação entre } \\
\text { as variáveis de } \\
\text { informatização e as } \\
\text { variáveis de } \\
\text { desempenho das } \\
\text { concessionárias de } \\
\text { automóveis brasileiras }\end{array}$ & $\begin{array}{l}\text { Correlação de } \\
\text { Spearman }\end{array}$ & $\begin{array}{l}26 \text { variáveis distintas, entre as } 58 \\
\text { variáveis de informatização } \\
\text { consideradas apresentaram } \\
\text { correlações significativas com oito } \\
\text { das nove variáveis de impacto } \\
\text { testadas }\end{array}$ & $\mathrm{TI}$ \\
\hline $\begin{array}{l}\text { Alves, Silva, } \\
\text { Fonseca } \\
\text { (2007) }\end{array}$ & $\begin{array}{l}\text { Examinar as } \\
\text { implicações da } \\
\text { adoção da TI para o } \\
\text { controle gerencial } \\
\text { exercido sobre o ciclo } \\
\text { de suprimentos do } \\
\text { Governo Federal }\end{array}$ & $\begin{array}{l}\text { Estudo de } \\
\text { caso }\end{array}$ & $\begin{array}{l}\text { Melhoria dos indicadores, com } \\
\text { aumento das despesas licitadas, } \\
\text { maior utilização do pregão e } \\
\text { ampliação do número de } \\
\text { fornecedores cadastrados }\end{array}$ & $\mathrm{TI}$ \\
\hline $\begin{array}{l}\text { Luciano, } \\
\text { Testa, } \\
\text { Rohde } \\
\text { (2007) }\end{array}$ & $\begin{array}{l}\text { Identificar a } \\
\text { percepção dos } \\
\text { benefícios da gestão } \\
\text { de serviços de TI, } \\
\text { bem como } \\
\text { dificuldades e }\end{array}$ & Survey & $\begin{array}{l}\text { Ainda não há uma visão clara de } \\
\text { todos os benefícios da gestão de } \\
\text { serviços de TI, em especial } \\
\text { aqueles com retornos indiretos ou } \\
\text { mais tênues }\end{array}$ & $\mathrm{TI}$ \\
\hline
\end{tabular}




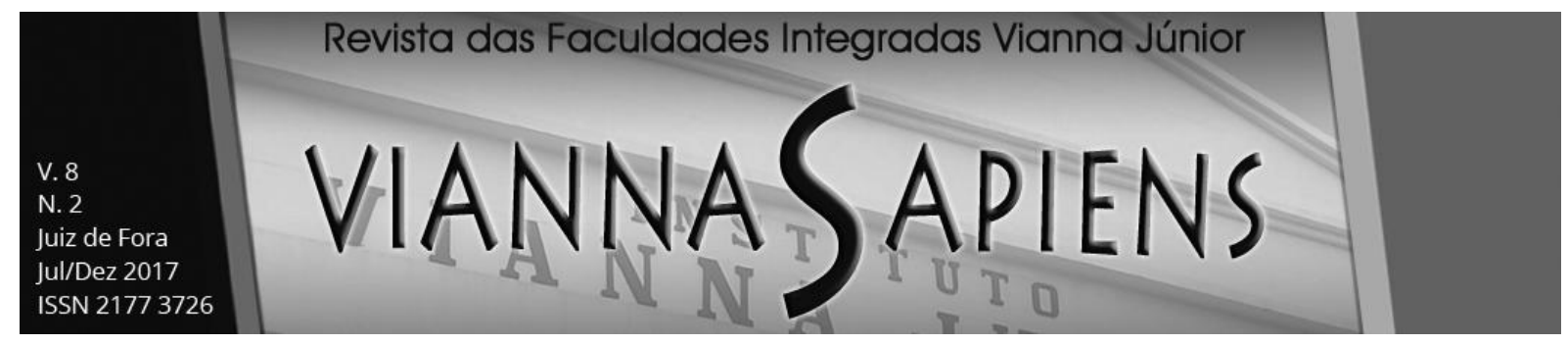

\begin{tabular}{|c|c|c|c|c|}
\hline & $\begin{array}{l}\text { caminhos para a sua } \\
\text { adoção }\end{array}$ & & & \\
\hline $\begin{array}{l}\text { Rodrigues, } \\
\text { Assolari } \\
\text { (2007) }\end{array}$ & $\begin{array}{l}\text { Compreender como o } \\
\text { ERP contribuiu e } \\
\text { ainda contribui para o } \\
\text { crescimento dos } \\
\text { negócios das } \\
\text { empresas } \\
\text { pesquisadas }\end{array}$ & $\begin{array}{l}\text { Estudo de } \\
\text { caso }\end{array}$ & $\begin{array}{l}\text { Em todas as empresas } \\
\text { entrevistadas a utilização do ERP } \\
\text { trouxe benefícios e contribuições } \\
\text { nos negócios }\end{array}$ & $\begin{array}{l}\mathrm{TI}, \\
\text { Artefato } \\
\text { de TI }\end{array}$ \\
\hline $\begin{array}{l}\text { Santos, } \\
\text { Riboldy, } \\
\text { Fonseca, } \\
\text { Bovo (2006) }\end{array}$ & $\begin{array}{l}\text { Avaliar em que } \\
\text { medida o uso de TI } \\
\text { pode contribuir para o } \\
\text { aprimoramento da } \\
\text { ação "Gestão do } \\
\text { Imposto sobre Serviço } \\
\text { de Qualquer Natureza } \\
\text { (ISSQN)" }\end{array}$ & $\begin{array}{l}\text { Estudo de } \\
\text { caso }\end{array}$ & $\begin{array}{l}\text { A incorporação da TI permitiu ao } \\
\text { governo o desenvolvimento de } \\
\text { ações mais eficazes e efetivas no } \\
\text { que tange à gestão do ISSQN }\end{array}$ & $\mathrm{TI}$ \\
\hline $\begin{array}{l}\text { Rezende, } \\
\text { Guagliardi } \\
\text { (2006) }\end{array}$ & \begin{tabular}{|l} 
Analisar os \\
instrumentos de \\
planejamento \\
municipal e as \\
contribuições da TI na \\
gestão de prefeituras
\end{tabular} & $\begin{array}{l}\text { Estudo de } \\
\text { caso }\end{array}$ & $\begin{array}{l}\text { Dificuldades das prefeituras na } \\
\text { organização dos dados municipais, } \\
\text { na disponibilização de informações } \\
\text { e nos planejamentos para fins de } \\
\text { controle }\end{array}$ & $\mathrm{TI}$ \\
\hline $\begin{array}{l}\text { Souto, Dill } \\
\text { (2006) }\end{array}$ & $\begin{array}{l}\text { Discutir o controle e } \\
\text { sua evolução } \\
\text { considerando as } \\
\text { influências trazidas } \\
\text { pela introdução das } \\
\text { tecnologias } \\
\text { informacionais nos } \\
\text { mais variados } \\
\text { processos da } \\
\text { organização }\end{array}$ & $\begin{array}{l}\text { Estudo de } \\
\text { caso }\end{array}$ & $\begin{array}{l}\text { Relação entre a adoção do ERP e } \\
\text { transformações ocorridas em } \\
\text { diferentes intensidades no controle } \\
\text { organizacional }\end{array}$ & $\begin{array}{l}\text { TI, } \\
\text { Artefato } \\
\text { de TI }\end{array}$ \\
\hline $\begin{array}{l}\text { Pires, } \\
\text { Yamamoto, } \\
\text { Filho (2006) }\end{array}$ & $\begin{array}{l}\text { Validar e reespecificar } \\
\text { a construção de } \\
\text { modelo teórico com } \\
\text { base no trabalho de } \\
\text { Venkatesh et al. } \\
\text { (2003) }\end{array}$ & Survey & $\begin{array}{l}\text { Possibilidade de predizer intenção } \\
\text { de comportamento de uso do } \\
\text { referido serviço a partir de } \\
\text { expectativa de performance }\end{array}$ & $\mathrm{TI}$ \\
\hline $\begin{array}{l}\text { Almeida, } \\
\text { Gonçalves, } \\
\text { Novaes, } \\
\text { Simonetti } \\
(2006)\end{array}$ & $\begin{array}{l}\text { Analisar os impactos } \\
\text { da implantação de } \\
\text { sistemas de TI numa } \\
\text { instituição de saúde }\end{array}$ & $\begin{array}{l}\text { Estudo de } \\
\text { caso }\end{array}$ & $\begin{array}{l}\text { Houve aceitação da implantação } \\
\text { de tecnologia de informação }\end{array}$ & $\mathrm{TI}$ \\
\hline
\end{tabular}




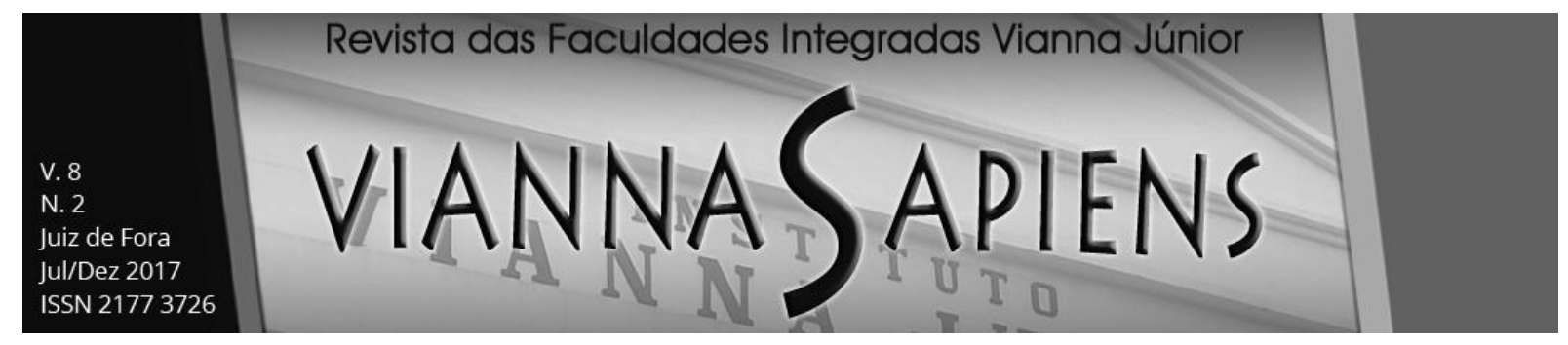

\begin{tabular}{|c|c|c|c|c|}
\hline $\begin{array}{l}\text { Luciano, } \\
\text { Testa, } \\
\text { Freitas } \\
(2006)\end{array}$ & $\begin{array}{l}\text { Definir um conjunto } \\
\text { de elementos, a partir } \\
\text { do COBIT, para } \\
\text { melhor gerenciar e } \\
\text { controlar uma } \\
\text { terceirização através } \\
\text { de BSP (Business } \\
\text { Server Provider) }\end{array}$ & $\begin{array}{l}\text { Estudo de } \\
\text { caso }\end{array}$ & $\begin{array}{l}\text { Necessidade de adaptação dos } \\
\text { controles do COBIT à terceirização }\end{array}$ & $\mathrm{TI}$ \\
\hline $\begin{array}{l}\text { Gama, } \\
\text { Magnos } \\
\text { Martinello } \\
(2006)\end{array}$ & $\begin{array}{l}\text { Analisar como o } \\
\text { departamento de TI } \\
\text { de uma empresa do } \\
\text { setor siderúrgico está } \\
\text { exercendo a } \\
\text { governança }\end{array}$ & $\begin{array}{l}\text { Estudo de } \\
\text { caso }\end{array}$ & $\begin{array}{l}\text { Não tem havido correlação positiva } \\
\text { entre o nível de Governança de TI } \\
\text { e a performance das métricas } \\
\text { operacionais }\end{array}$ & $\mathrm{TI}$ \\
\hline $\begin{array}{l}\text { Favoreto, } \\
\text { Ishikawa, } \\
\text { Favoreto, } \\
\text { Aquino, } \\
\text { Favoreto } \\
\text { (2006) }\end{array}$ & $\begin{array}{l}\text { Elencar impactos } \\
\text { favoráveis dos } \\
\text { recursos de TI sobre } \\
\text { a comunicação } \\
\text { interna }\end{array}$ & Exploratório & $\begin{array}{l}\text { Impactos causados pela TI } \\
\text { bastante úteis às organizações } \\
\text { modernas, face ao contexto } \\
\text { ambiental }\end{array}$ & $\mathrm{TI}$ \\
\hline $\begin{array}{l}\text { Galas, Érico } \\
\text { Veras } \\
\text { Marques } \\
(2006)\end{array}$ & $\begin{array}{l}\text { Avaliar os impactos } \\
\text { do grau de } \\
\text { importância dos } \\
\text { fatores na avaliação } \\
\text { do nível de } \\
\text { alinhamento da TI } \\
\text { com o negócio }\end{array}$ & Exploratório & $\begin{array}{l}\text { O estudo demonstrou que o grau } \\
\text { de importância dos fatores } \\
\text { influencia na avaliação do nível de } \\
\text { alinhamento da TI com o negócio }\end{array}$ & $\mathrm{TI}$ \\
\hline $\begin{array}{l}\text { Mello, Stal, } \\
\text { Queiroz } \\
\text { (2006) }\end{array}$ & $\begin{array}{l}\text { Analisar o avanço } \\
\text { tecnológico } \\
\text { proporcionado pela TI } \\
\text { no setor de serviços } \\
\text { bancários, } \\
\text { especialmente no } \\
\text { Internet banking }\end{array}$ & $\begin{array}{l}\text { Estudo de } \\
\text { caso }\end{array}$ & $\begin{array}{l}\text { Necessidade de ampliação do } \\
\text { conhecimento do banco acerca do } \\
\text { cliente, como algo essencial para } \\
\text { melhorar a eficiência e a eficácia } \\
\text { do atendimento }\end{array}$ & $\mathrm{TI}$ \\
\hline
\end{tabular}

Fonte: elaborado pelos autores 


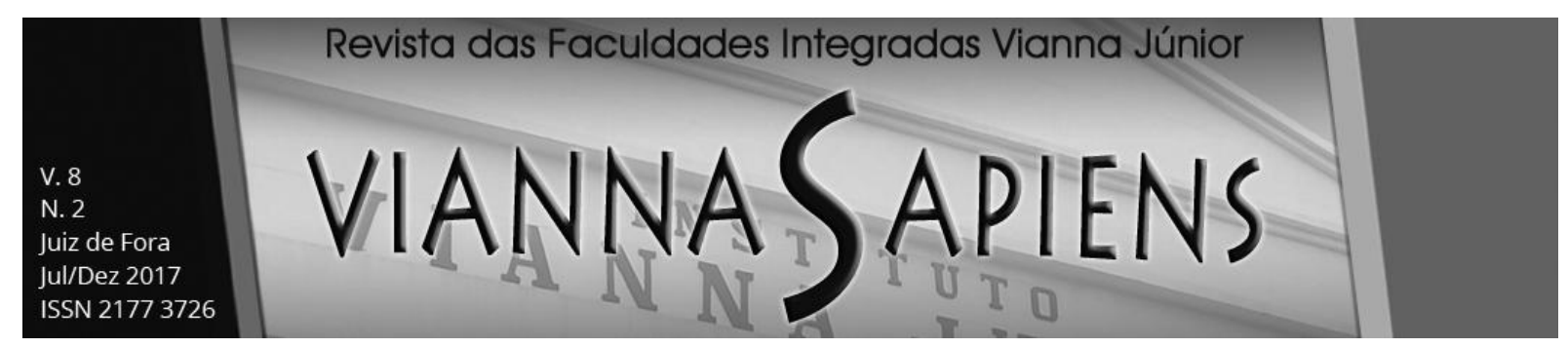

Quadro 3. Pesquisas sobre rotinas organizacionais

\begin{tabular}{|l|l|l|l|l|}
\hline Autores & Objetivos do Estudo & Metodologia & $\begin{array}{l}\text { Principais } \\
\text { Resultados }\end{array}$ & $\begin{array}{l}\text { Conceitos } \\
\text { Encontrados }\end{array}$ \\
\hline $\begin{array}{l}\text { Spuldaro } \\
(2013)\end{array}$ & $\begin{array}{l}\text { Propor um } \\
\text { complemento à } \\
\text { abordagem } \\
\text { institucional das } \\
\text { rotinas }\end{array}$ & $\begin{array}{l}\text { Ensaio } \\
\text { Teórico }\end{array}$ & $\begin{array}{l}\text { Proposição para } \\
\text { estudar a } \\
\text { capacidade de } \\
\text { agência e rotinas } \\
\text { com troca de } \\
\text { membros }\end{array}$ & $\begin{array}{l}\text { Rotinas } \\
\text { organizacionais }\end{array}$ \\
\hline $\begin{array}{l}\text { Raupp, } \\
\text { Pegorini, } \\
\text { Recker e } \\
\text { Ruas } \\
\text { (2013) }\end{array}$ & $\begin{array}{l}\text { Pesquisar a relação } \\
\text { existente entre rotinas } \\
\text { de aprendizagem e a } \\
\text { consolidação de } \\
\text { determinadas } \\
\text { competências } \\
\text { organizacionais }\end{array}$ & $\begin{array}{l}\text { Estudo de } \\
\text { caso }\end{array}$ & $\begin{array}{l}\text { Descrevem } \\
\text { elementos de } \\
\text { aprendizagem que } \\
\text { reforçam as } \\
\text { competências } \\
\text { organizacionais }\end{array}$ & $\begin{array}{l}\text { Rotinas } \\
\text { organizacionais }\end{array}$ \\
\hline
\end{tabular}

Fonte: elaborado pelos autores

Quadro 4. Pesquisas sobre artefatos (gestão da informação)

\begin{tabular}{|l|l|l|l|l|}
\hline Autores & Objetivos do Estudo & Metodologia & $\begin{array}{l}\text { Principais } \\
\text { Resultados }\end{array}$ & $\begin{array}{l}\text { Conceitos } \\
\text { Encontrados }\end{array}$ \\
\hline $\begin{array}{l}\text { De Sordi, } \\
\text { Meireles } \\
(2014)\end{array}$ & $\begin{array}{l}\text { Apresentar um } \\
\text { artefato de software, } \\
\text { para analisar a coesão } \\
\text { entre as seções de } \\
\text { textos. }\end{array}$ & $\begin{array}{l}\text { Design } \\
\text { science } \\
\text { research }\end{array}$ & $\begin{array}{l}\text { A percepção dos } \\
\text { usuários } \\
\text { demonstrou a r a } \\
\text { eficácia rato de TI } \\
\text { software do em } \\
\text { identificar r de } \\
\text { problemas de } \\
\text { coesão em textos } \\
\text { extensos }\end{array}$ & \\
& & & & \\
\hline
\end{tabular}

Fonte: elaborado pelos autores 


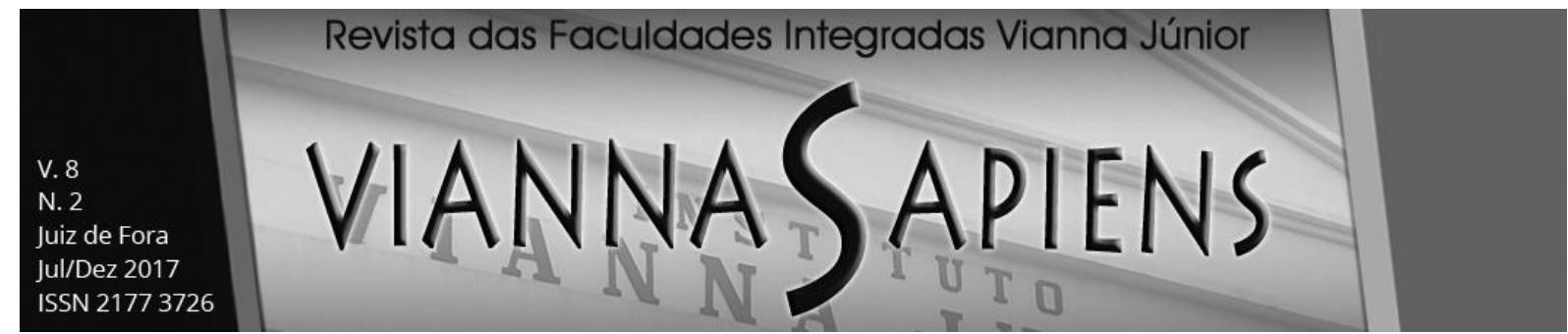

Em uma análise preliminar do campo, é possível perceber a importância dos estudos sobre tecnologia da informação. Pelos artigos encontrados, observa-se que as pesquisas envolvendo gestão e governança de TI, em geral, apontam para questões envolvendo medição de desempenho organizacional, identificação de mecanismos adotados, mapeamento de competências do gestor, aparentemente preocupadas em medir o impacto do fenômeno tecnologia da informação no desempenho da organização. Em relação às rotinas organizacionais, tem-se nas últimas pesquisas uma enfoque cognitivo, voltado para o indivíduo, com foco na aprendizagem e na agência humana, e uma oportunidade de trabalhos voltados para o ambiente da prática e como as rotinas são criadas e estabelecidas. Em relação aos artefatos, a pesquisa analisada sugere uma ferramenta de produtividade específica, com uma atenção especial para os dispositivos móveis, mas estudados de forma desacoplada e autônoma, dentro da organização. Finalmente, não foram encontradas (ainda) pesquisas envolvendo a visão da sociomaterialidade, nem do entrelaçamento entre rotinas e artefatos, sugerindo um caminho promissor para futuros trabalhos.

\section{CONCLUSÕES}

É possível inferir que o que diferencia as organizações quanto ao uso que fazem da tecnologia está relacionado com a maneira com que são geridas e como suas rotinas estão constituídas e são executadas na prática. Para isso, torna-se necessário identificar quais fatores determinam a interação entre pessoas, tecnologia e processos num ambiente organizacional sob uma nova lente teórica, para melhor perceber o fenômeno da tecnologia e sua influência dentro da própria organização.

Destaca-se aqui a extrema importância e relevância dos trabalhos analisados. Entretanto, a proposta aqui estabelecida é de uma nova visão da organização, com 


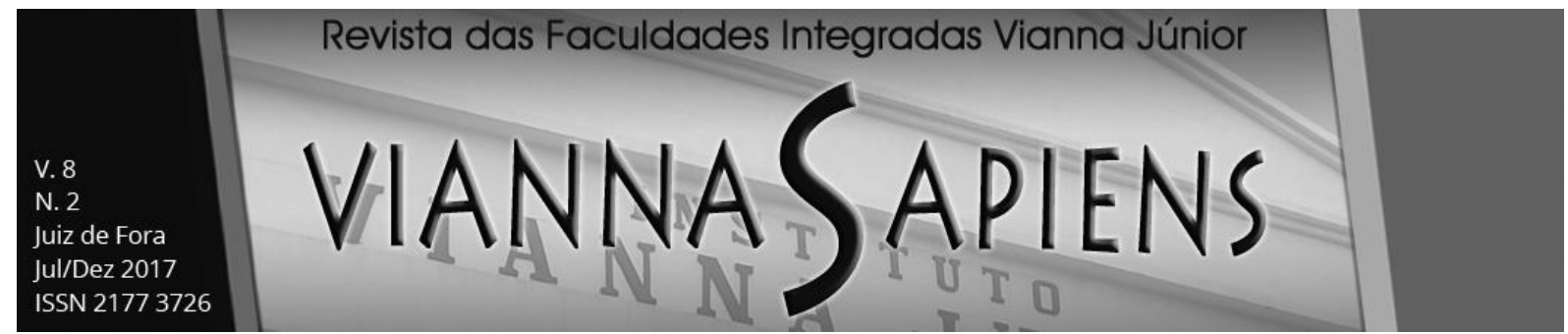

o argumento da necessidade de se compreender o processo de desenvolvimento de novas rotinas, com olhar para o surgimento de sistemas de artefatos, onde o social e o técnico são considerados únicos e entrelaçados, em uma perspectiva sociomaterial, ao invés de artefatos individuais analisados isoladamente. Nem todos os artefatos influenciam a organização da mesma maneira, nem através dos mesmos mecanismos (CACCIATORI, 2012; LEONARDI, 2011; ORLIKOWSKI, 2007).

Essa nova visão pode mudar a própria compreensão das rotinas, mostrando que os padrões observáveis e repetitivos de comportamento nas organizações são realizados por indivíduos conscientes, com poder de agência, e não por respostas fixas a estímulos pré-estabelecidos. Essa agência, ou capacidade dos indivíduos em alcançar seus objetivos, impacta nas rotinas, que mudam a todo o tempo. Para uma melhor compreensão destas novas rotinas, é necessário ir além do entendimento do indivíduo e examiná-lo no contexto de artefatos onde opera. Mesmo o papel dos artefatos nas rotinas ainda é controverso. Alguns autores reforçam seu papel na padronização do comportamento organizacional, enquanto outros já se preocupam com o conhecimento empregado no projeto dos artefatos, para ocasionar mudança nos processos organizacionais (CACCIATORI, 2012).

A interação entre a tecnologia e os atores sociais produz circunstâncias particulares onde as rotinas são criadas e estabelecidas. Uma abordagem em direção a esse objetivo implica rever as teorias existentes que já abordam a tecnologia de forma que elas incorporam uma perspectiva mais sociomaterial. Além disso, a sociomaterialidade pode oferecer uma lente teórica para auxiliar no entendimento das rotinas organizacionais, de modo a obter novos insigths para o entendimento do entrelaçamento entre o social e o material, explorando as diferentes visões que possam auxiliar na avaliação e implementação de novas tecnologias da informação nas organizações. 


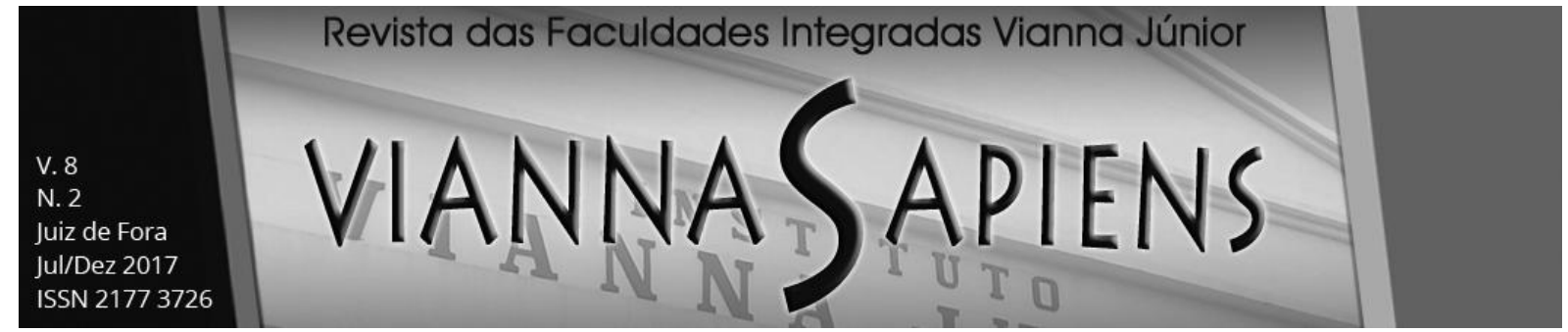

\title{
AN ANALYSIS OF INFORMATION TECHNOLOGY UNDER THE OPTICS OF SOCIOMATERIALITY
}

\begin{abstract}
Technology has become an integral part of most organizations. In fact, technologies are constantly evolving and transforming, creating new behaviors and bringing new phenomena to researchers for research in the context in which they find themselves. Specifically in information technology, there is a gradual change in the field of research, from more technical issues, linked to technology, to a more organizational view, with management and strategic information (ORLIKOWSKI and SCOTT, 2008). This change brings new challenges for research in the field, with promising approaches such as sociomateriality, which reconsiders the status of technology in organizational research. The aim of this paper is to present sociomateriality as a possible theoretical lens for conducting research on the implications of IT in organizations. To this end, it will be based on the notion that the sociomaterial aspect is not about technology but about the practice in which technology is embedded. The argument to be developed in this essay will be based essentially on three points: Orlikowski's view on sociomateriality; in establishing that technology can be represented and studied by its artifacts (responsible for the interaction of technology with social actors); and on the assumption that practices are amenable to interpretation through organizational routines: created and established, also, from the interaction between technology and social actors.
\end{abstract}

KEYWORDS: INFORMATION TECHNOLOGY. IT ARTIFACTS. RGANIZATIONAL ROUTINES.SOCIOMATERIALIDADE. 


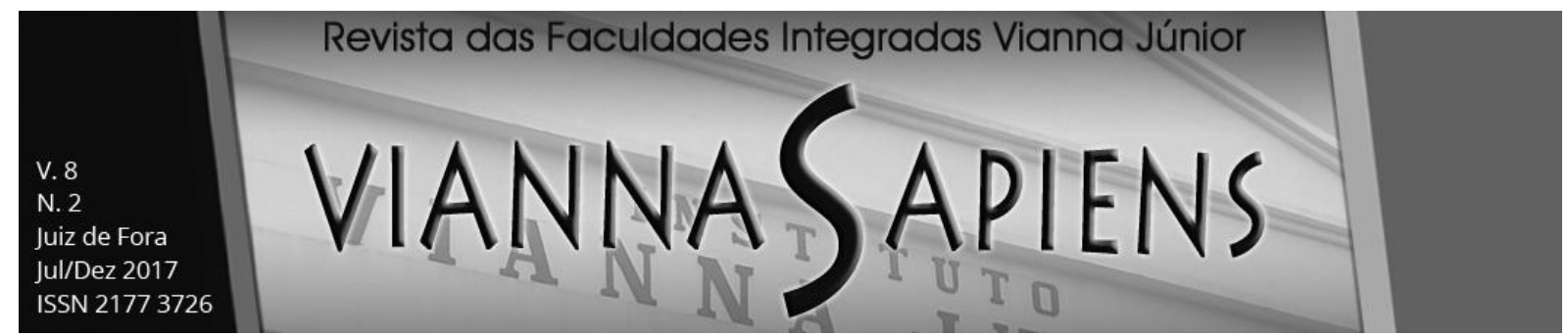

\section{REFERÊNCIAS}

BORGES M. E. N. A informação como recurso gerencial das organizações na sociedade do conhecimento. Ciência da Informação, Brasília, v. 24, n. 2, p. 181188, maio/ago. 1995.

BOUDREAU, Marie-Claude; ROBEY, Daniel. Enacting integrated information technology: A human agency perspective. Organization science, v. 16, n. 1, p. 318, 2005.

CACCIATORI, Eugenia. Resolving Conflict in Problem-Solving: Systems of Artefacts in the Development of New Routines. Journal of Management Studies, v. 49, n. 8, p. 1559-1585, 2012.

D'ADDERIO, Luciana. Artifacts at the centre of routines: Performing the material turn in routines theory. Journal of Institutional Economics, v. 7, n. 02, p. 197-230, 2011.

EMIRBAYER, Mustafa; MISCHE, Ann. What is agency? American journal of sociology, v. 103, n. 4, p. 962-1023, 1998.

GABLE G., Strategic information systems research: An archival analysis, The Journal of Strategic Information Systems, v.19 n.1, p.3-16, March, 2010.

HOWARD-GRENVILLE, J. A. The Persistence of Flexible Organizational Routines: The Role of Agency and Organizational Context. Organization Science. Vol. 16, No. 6, November-December 2005, pp. 618-636. 


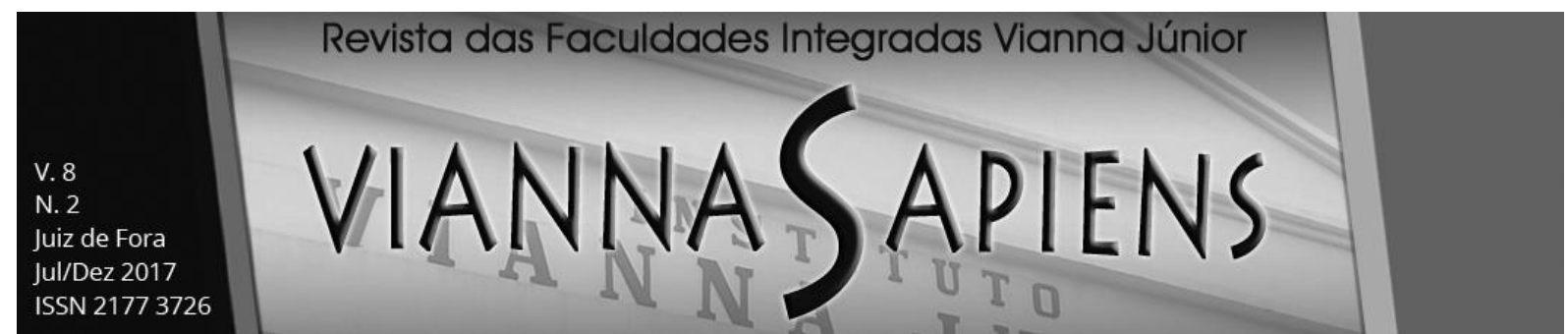

LAURINDO, Fernando José Barbin, et al. "O papel da tecnologia da informação (TI) na estratégia das organizações." Gestão \& Produção 8.2 (2001): 160-179.

LEONARDI, P. M. (2011). When flexible routines meet flexible technologies:

Affordance, constraint, and the imbrication of human and material agencies. MIS Quarterly, 35(1), 147-167.

LEONARDI, P. M., NARDI B. A., \& KALLINIKOS J. Materiality, Sociomateriality, and Socio-Technical Systems: What Do These Terms Mean? How Are They Related? Do We Need Them? Materiality and Organizing: Social Interaction in a Technological World (pp. 25-48). Oxford: Oxford University Press, 2012.

LUFTMAN, J.N. Competing in information age: strategic aligment in pratice. Oxford university, 1996.

MANSELL, Robin, Avgerou, CHRISANTHI, Quad, DANNY \& Silverstone, ROGER. The Oxford Handbook of Information and Communication Technologies, Oxford, 2007.

MCLEOD, L.; MACDONELL, S. G.; DOOLIN, B. Qualitative research on software development: a longitudinal case study methodology. Empirical software engineering, v. 16, n. 4, p. 430-459, 2011.

MORAES, G. D. A., Terence, A. C. F., Escrivão Filho, E. A Tecnologia da Informação Como Duporte à Gestão Estratégica da Informação na Pequena Empresa. Revista de Gestão da Tecnologia e Sistemas de Informação. Vol. 1, No. 1, 2004, pp. 2743 


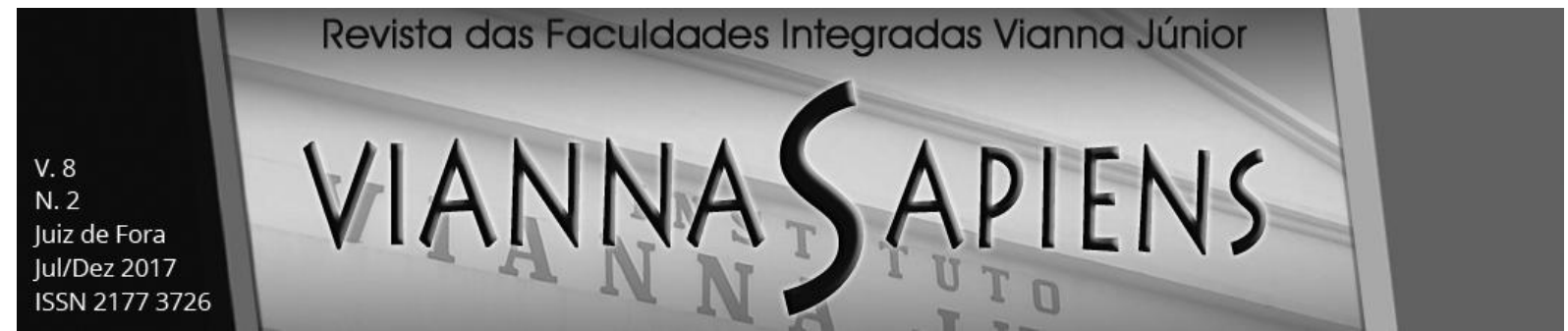

ORLIKOWSKI, W.J., and IACONO, C.S. 2001. "Desperately Seeking The "IT" In IT Research - a Call to Theorizing the IT Artifact," Information Systems Research (12:2), June, pp. 121-134.

ORLIKOWSKI, W. J. (2007). Sociomaterial practices: Exploring technology at work. Organization Studies, 28(9), 1435-1448.

ORLIKOWSKI, W.J. and SCOTT, S. V. 2008. "Sociomateriality: Challenging the Separation of Technology, Work and Organization," Annals of the Academy of Management, 2, 1:433-474.

PARMIGIANI, A.; HOWARD-GRENVILLE, J. Routines Revisited: Exploring the Capabilities and Practice Perspectives. The Academy of Management Annais. Vol. 5, No. 1, June 2011, 413-453.

PENTLAND, B. T. FELDMAN, Martha S. Reconceptualizing OR as flexibility and change. Administrative Science Quarterly, 48 (2003): 94-118.

PENTLAND, Brian T.; FELDMAN, Martha S. Organizational routines as a unit of analysis. Industrial and corporate change, v. 14, n. 5, p. 793-815, 2005.

PORTER, Michael E. \& MILLAR, Victor E. How information gives you competitive advantage. Harvard Business Review, Boston, Jul/Aug 1985.

ZHANG, P., SCIALDONE, M., and KU, M. C. 2011. IT artifacts and the state of IS research. In Proceedings of the International Conference on Information Systems (Shanghai, China, December 04 - 07, 2011). 